\title{
Quantifying and Generalizing Hydrologic Responses to Dam Regulation using a Statistical Modeling Approach
}

\section{Ryan A. McManamay ${ }^{1}$}

Environmental Sciences Division, Oak Ridge National Laboratory, Oak Ridge, TN 37831

${ }^{1}$ Environmental Sciences Division, Oak Ridge National Laboratory

PO Box 2008 MS6351

Oak Ridge, TN 37831-6351

Office phone: $865-241-8668$

Fax: 865-576-9938

Email:mcmanamayra@ornl.gov 


\begin{abstract}
Despite the ubiquitous existence of dams within riverscapes, much of our knowledge about dams and their environmental effects remains context-specific. Hydrology, more than any other environmental variable, has been studied in great detail with regard to dam regulation. While much progress has been made in generalizing the hydrologic effects of regulation by large dams, many aspects of hydrology show site-specific fidelity to dam operations, small dams (including diversions), and regional hydrologic regimes. A statistical modeling framework is presented as a predictive tool to quantify and generalize hydrologic responses to varying degrees of dam regulation at large spatial scales. In addition, the approach provides a method to expand sample sizes beyond that of traditional dam-hydrologic-effect analyses. Model performance was relatively poor with models explaining $10-31 \%$ of the variation in hydrologic responses. However, models had relatively high accuracies (61-89\%) in classifying the direction of hydrologic responses as negative or positive. Responses of many hydrologic indices to dam regulation were highly dependent upon regional hydrology, the purpose of the dam, and the presence of diversion dams. In addition, models revealed opposite effects of dam regulation in systems regulated by individual dams versus many upstream dams, suggesting that the effects of dams may be countered by other dams in basins experiencing intensified cumulative disturbance. Results also suggested that particular contexts, including multipurpose dams, high cumulative regulation, diversions, and regions of unpredictable hydrology are all sources of increased error when predicting hydrologic responses to dams. Statistical models, such as the ones presented herein, show promise in their ability to generalize the directionality of hydrologic responses to dam regulation and provide parameter coefficients to inform future site-specific modeling efforts.
\end{abstract}




\section{Keywords}

Environmental flow; hydrologic alteration; ELOHA; flow-ecology relationships; hydrologic classification 


\section{Introduction}

Despite the ubiquitous existence of dams within riverscapes, much of our knowledge about dams and their environmental effects remains context-specific. Contextual knowledge regarding eco-biophysical, societal, or economic patterns of dams stems from research conducted in a few locations, focusing on only large dams rather than a representative sample size, and lack of long-term monitoring (Graf, 2005). Policies and regulations have also contributed to the context-specific nature of dam-related environmental relationships by limiting the ability to develop generalizable trends across multiple facilities and scales, despite differences in dam ownership and purpose (Graf, 2005).

Hydrology, more than any other environmental variable, has been studied in great detail with regard to dam regulation. Indeed, dam-induced hydrologic responses have shown great promise in displaying generalizable trends to support broadly-applicable theories (Poff et al., 1997), including potential ecological responses to altered streamflow conditions (Poff et al., 2010; Carlisle et al., 2011). In general, dams are hypothesized to homogenize flows across distinct hydroclimatic regions (Poff et al,. 2007) by decreasing maximum flows, rise and fall rates, and flow variability while also increasing minimum flows (Magilligan and Nislow, 2001, 2005; Maingi and Marsh, 2002; Nislow et al., 2002; Batalla et al., 2004; Pyron and Neumann, 2008; Fitzuh and Vogel, 2011). However, minimum flows and baseflow indices may display variable responses to dam regulation depending on regional hydrology (McManamay et al., 2012). In addition, seasonal magnitudes, duration, frequency, and timing of flows seem to show far more site-specific fidelity to dam operations and regional hydrologic regimes (Richter et al., 1996; Batalla et al., 2004; Magilligan and Nislow, 2005; Pyron and Neumann, 2008; McManamay et al., 2012). Thus, a modeling framework to quantify and generalize the 
hydrologic the effects of dams across large spatial scales would be beneficial for multiple reasons, such as predicting hydrologic alteration in ungauged basins (e.g. Eng et al., 2012), quantifying the degree of hydrologic alteration in the landscape (Richter et al., 1998), and providing a rapid assessment of potential hydrologic changes priori to dam development (especially in countries facing intense development). Such an exploratory technique could inform basin planning efforts and provide a priori parameter estimates for future site-specific hydrologic modeling efforts. Furthermore, a fundamental knowledge gap in developing environmental flow standards is generalizing hydrologic responses, and associated ecological responses, to landscape disturbances (Poff et al., 2010). In cases of inadequate information or predictive tools, water policy standards are many times presumed, rather than quantified, thresholds of hydrologic change, above which are cause deleterious ecological effects (Richter et al., 2012).

Given the complicated nature of predicting hydrologic changes induced by damregulation, most approaches linking dam operations to downstream flows are context-specific in that they isolate the hydrologic effects of individual dams. The vast majority of these approaches rely on analyzing discharge information collected during periods prior to and following dam construction (e.g., Richter et al., 1996; Nislow et al., 2002; Gao et al., 2009). This requires either considering the effects of dams in isolation or, if desiring to build stream observation datasets that consider multiple dams, it requires isolating the effects of an individual dam on each stream gauge. To ensure stream gage records reflect the influence of a single dam, stringent criteria are imposed to isolate the individual dam-related effects, such as 1) adequate pre- and post- dam regulation discharge information, 2) no additional dam regulation besides the dam of interest, 3) short distances between dam and stream gauge, 4) very few tributaries between dam and stream gage, and 5) very little additional watershed disturbances, such as urbanization (e.g., Poff et al., 
2007; Gao et al., 2009). Ultimately this restricts sample sizes and limits the conclusions drawn from such analyses because typically only large dams with long historical records are considered (Graf, 2005).

As opposed to relying on pre- and post-hydrologic information, other approaches isolate individual-dam effects by developing algorithms to optimize reservoir releases based on available inflow and outflow information (Yeh, 1985; Wurbs, 1993; Labadie, 2004). Optimal reservoir release scenarios are usually developed for only one to a few dams and provide a mechanism to balance ecological and societal needs regarding water use. Nonetheless, reservoir operation algorithms can be quite complex, incorporating stochastic variation based on forecasted inflows (Stedinger et al., 1984), parameter uncertainty in reservoir release simulations (Stedinger et al., 1985), and uncertainty in reservoir operation rules based on fuzzy modeling (Shrestha et al., 1996). Until recently, incorporating reservoir operations into larger scale process-based hydrologic models (e.g., SWAT- Soil and Water Assessment Tool) was nonexistent (Bouraoui et al., 2005), time and resource intensive (e.g., Vörösmarty and Moore, 1991), or limited in application (Arnold and Fohrer, 2005). Most current process-based or routing hydrologic models support reservoir routing applications by incorporating algorithms dependent upon simulated inflows, dam purpose, evaporation, storage capacity, and water demands (Haddeland et al., 2007; Hanasaki et al., 2006; Zhang et al., 2010, 2011; Kalogeropoulos et al., 2011). Because process-based modeling is time-intensive, most applications incorporating reservoir effects have been applied at the basin-level (e.g., Zhang et al., 2010, 2011; Kalogeropoulos et al., 2011). However, global river routing models have been developed that incorporate reservoir operations, typically from the largest reservoirs with adequate documentation (Döll et al., 2003; Hanasaki et al., 2006). Nonetheless, this approach requires 
isolating reservoirs with adequate information, simulating inflows for each reservoir, and assuming reservoir operations based on available information. For example, Hanasaki et al. (2006) simulated reservoir operations for 452 reservoirs occurring globally using existing reservoir datasets, global river routing discharge information, and water use information. Process-based models are highly informative because they provide a mechanistic understanding of water routing through the landscape and infrastructure and provide simulated hydrographs at relevant time-steps. However, incorporating dam regulation effects into process-based models requires making assumptions a priori, which becomes more difficult and error-prone at larger spatial scales. Furthermore, error propagation can be severe in river systems with many dams, especially multipurpose dams.

In contrast to developing process-based model structure, statistical models are relatively inexpensive (in terms of time) to develop, can be applied at large spatial scales, and typically require less a priori assumptions as their process-based counterparts. In addition, statistical models can be used as an exploratory technique or a pre-cursor to process-based models by providing boundaries to parameter estimates and informing the development of reservoir operation algorithms. However, statistical approaches developed to quantify the effects of damregulation at large spatial scales requires consideration of four main factors: 1) expanding sample sizes beyond available pre- and post-dam regulation data, 2) incorporating information on cumulative dam regulation in addition to isolating individual dam effects, 3 ) incorporating other watershed disturbances besides dam-related effects, 4) accounting for differences in regional hydrologic contexts, and 5) characterizing sources of error in accurately predicting hydrologic responses to dam regulation. The purpose of this study was to construct a statistical modeling framework to predict the complex hydrologic effects of dam regulation on streams by addressing 
the five main factors mentioned above. Specifically, pre-dam regulation conditions are modeled to boost sample sizes to support large-scape modeling efforts. In order to quantify and generalize dam effects on hydrology, differences in individual versus cumulative effects of dam regulation and differences in dam operations (i.e., purpose and diversions) were considered in a series of alternative models. To understand the importance of regional natural flow regimes, hydrologic classes, groups of streams with similar hydrology, were incorporated as structural component of models. Lastly, the relative contribution of different regulation contexts to error in models predicting hydrologic responses to dams was also considered.

\section{Methods}

\subsection{Overview of Statistical Modeling Approach}

To model hydrologic responses to dam regulation, a series of steps were required, including assembling stream gauges regulated by dams (section 2.2), quantifying hydrologic responses (section 2.3), assembling relevant predictors of dam regulation (section 2.4), and then building alternative statistical models (section 2.5). Each of these steps are described more thoroughly in the following sections. Hydrologic responses were quantified in two approaches depending on gauge records. First, for gauge records extending prior to dam construction, hydrologic changes were quantified using discharge information from pre- and post- dam regulation periods. For gauge records not extending prior to dam construction, pre-dam regulation conditions had to be predicted using models (i.e. random forests). Predictors describing local dam characteristics (e.g., storage, purpose, diversions), cumulative dam characteristics (e.g., cumulative upstream storage), and non-dam-related disturbances (e.g., urbanization) were summarized and used in models. Statistical models were then constructed 
using Generalized Linear Mixed Models as these provide means to incorporate structure, such a regional hydrologic context.

\subsection{Selecting stream gauges regulated by dams}

In order to evaluate varying degrees of dam-regulation, a diverse dataset of stream gauges occurring at variable distances downstream of small to large dams and along a gradient of low to intense cumulative regulation would be ideal. Given that the purpose of this study was to model the effect of these attributes, the criteria for selecting dam-regulated stream gauges was quite liberal, with the exception of insuring the main cause of hydrologic modification was, in fact, dam regulation. McManamay et al. (2014) previously selected 1180 USGS stream gauges regulated by dams (Figure 1) and the methodology they used is expanded here. Two databases were used to selected dam-regulated gages: the Geospatial Attributes of Gages for Evaluating Streamflow (GAGES) (Falcone et al., 2010; Falcone, 2011) and the National Inventory of Dams (NID) (USACE, 2013). The GAGES database was a national effort to compile natural and anthropogenic information in the upstream watersheds of 9322 USGS stream gauges. The database classifies gauges based on reference or non-reference hydrologic condition and provides a suite of variables useful for identifying causal mechanisms for hydrologic alteration, such as information on dam regulation, urbanization, withdrawals. In addition, GAGES provides text on hydrologic conditions from the USGS Annual Water Data Reports (ADRs) along with additional screening comments from regional experts (Falcone et al., 2010). ADR reports and screening comments provide expert judgment on the extent and cause of hydrologic alterations, including dam regulation. Typically, ADR reports provide the name(s) of the dam contributing to regulation and the year in which dam regulation was initiated. The NID has comprehensive 
information for dams in the USA including their purpose, dimensions, storage capacity, contributing drainage area, river name, and year built.

[Figure 1 here]

A four-step screening criteria was used to identify dam-regulated gauges: 1) gauges with at least 1 major dam upstream, 2) gauges below hydroelectric facilities, 3) ADR reports indicating regulation by 1 or more dams, and 4) the stream gauge's period of record having at least 15 years post-dam regulation. Major dams are defined as structures $\geq 15$-m heights or $\geq 6167$-Ml storage capacity (Falcone et al., 2010). Using the GAGES database, gauges with at least 1 major dam in their contributing watershed and having at least a 15 -year period of record were selected. Additional emphasis was placed on capturing non-major dams used to generate hydroelectric energy because their operation may disproportionately influence downstream hydrology relative to their size. The locations of hydroelectric dams were obtained from Oak Ridge National Laboratory's NHAAP database (ORNL, 2014). Using a spatial join procedure in ARC Map 9.3, USGS stream gauges falling within $15 \mathrm{~km}$ were linked to each hydroelectric dam and then manually reviewed to select the closest downstream gauge.

All gauges from criteria 1 and 2 were then screened individually for comments indicating the cause of hydrologic alteration was dam regulation. Gauges were included if ADR reports used descriptors, such as "regulated by", "regulation", "powerplant", and "afterbay", and provided the specific name of the nearest upstream dam and/or alluding to cumulative dam regulation were included. Gauges with ADR reports describing diversion scenarios were also included if they also mentioned the dam responsible for diverting water. In order to ensure gage records did not precede dam regulation, ADR reports and spatial analyses were used to account 
for the year of construction of dams upstream of each gauge and their year of construction. Typically, the earliest year(s) of regulation by the dam(s) inducing the majority of control over hydrology at each gauge was provided within the ADR report. However, an assessment was required to ensure dates of major dam construction were accurate and the construction of smaller, influential dams was not occurring in the basin after the date of initial regulation. To avoid including smaller off-channel agriculture ponds, only dams $>6 \mathrm{~m}$ in height were selected and their latitudes and longitudes were imported into ARC Map 9.3. Boundaries for the contributing watershed above each stream gage were provided by Gages II. Using a spatial join procedure, NID dams were linked to each gauge's watershed and each gauge was individually assessed to determine the first and last year of dam construction in the basin. Non-major dams comprising only $5 \mathrm{Ml}$ per km-2 of basin area tend to show little influence on hydrologic patterns (McManamay et al., 2014). Hence, the date of construction for these dams was ignored if the following conditions were met: 1) they preceded the initial year of regulation by a major dam occurring closer to the gage and 2) did not contribute to more than $5 \mathrm{Ml} \mathrm{km}^{-2}$ to cumulative upstream storage if accompanied by other smaller dams. Gauge records were updated to reflect regulation following the last year of influential dam construction in the basin.

\subsection{Building a hydrologic response dataset}

To characterize hydrology, 37 hydrologic indices were selected based on their ability to describe all five key components of the flow regime (magnitude, frequency, duration, timing, and rate of change) (Poff et al., 1997) and their use in previous studies assessing dam-regulation (McManamay et al. 2012, 2013b). The indices including the 33 Indicators of Hydrologic Alteration (Richter et al. 1997, 1998), mean annual runoff, daily CV flow, predictability of flow, and frequency of high flows $3 X$ median flow (Olden et al., 2003) (Table 1). Mean daily stream 
flow data for the 1180 gauges were downloaded from the USGS National Water Information System. Discharge records were evaluated to ensure only time periods following the latest dam construction were evaluated. Discharge records were imported into the Hydrologic Index Tool (HIT) software (Henriksen et al., 2006) to calculate hydrologic indices.

Although all 1180 gauges contained post-dam regulation records, information on pre-dam regulation regimes was needed to adequately characterize hydrologic changes (from natural flow conditions) induced by dam regulation. Pre-dam regulation regimes were determined in two ways: 1) isolating gauges with records proceeding dam construction, or 2) using models to predict reference-condition hydrology for dam-regulated gauges. Each record was examined to determine if at least 15 years of data was available prior to dam regulation in the upstream basin according to McManamay et al. (2014). Each gauge record was individually compared to the earliest date of construction for all dams exceeding a cumulative storage of $5 \mathrm{Ml} \mathrm{km}^{-2}$. Historical patterns in other watershed disturbances (e.g. urbanization, withdrawals) were also used to determine any disturbances prior to dam construction (see McManamay et al., 2012 for methods). In addition, plots of hydrologic records pre-regulation and post-regulation were visualized to ensure that apparent changes were associated with regulation. A total of 237 gauges (of the 1180) had sufficient pre-dam regulation data. Pre-dam regulation records were isolated from the entire period of record (accounting for 2 years of construction) for each gauge and all 37 hydrologic indices were calculated using HIT.

For the remaining 943 gauges, records were insufficient in length or included other disturbances and thus, models would be required to estimate pre-dam hydrologic conditions. A reference dataset of 2618 gauges was developed for the entire US and included records from the 237 gauges with pre-dam information (McManamay et al. 2014). Using the reference dataset, 
random forest models (Breiman, 2001; Cutler et al., 2007) were used to predict pre-dam values for 35 hydrologic indices for the 943 gauges without pre-dam hydrologic information. Models were constructed using 77 climate and landscape predictors hypothesized to influence hydrology, including precipitation, temperature, basin topography, and soil information summarized within the watershed upstream of each gauge (McManamay et al., 2014). Random forests generate a large number of trees $(\sim 500)$ and then combine the predictions from all trees. A random subset of variables and a bootstrap subsample of the data (63\% of 2618 gauges) are used to construct each tree. The remaining samples [out-of-bag (OOB) observations] are used in a cross-validation procedure to calculate \% variance explained and root-mean-square-error (RMSE). RMSE values were normalized (NRMSE) by dividing by the RMSE value by the range of values for each hydrologic index. Hydrologic variables were $\log (x+1)$ transformed prior to developing random forests. Because of poor performance in random forests, Julian date of annual maximum and minimum were dropped from subsequent analyses.

Using pre- and post-hydrologic indices, a response ratio was calculated as (post value pre value) / pre value. For gauges with 0 values for pre-hydrologic indices, we assigned response ratios $=1$ if post-hydrologic index values were $>1$ and response ratios $=0$ if post values were 0 . Although response ratios for individual hydrologic indices are informative, an index that takes into account multiple hydrologic indices simultaneously would be advantageous. In addition, such an index might also provide a measure of overall departure from the normal tendency of reference stream conditions. Hydrologic classes represent a typical range of variation found in natural flow regimes. Hence, if a regulated gauge can be assigned to a hydrologic class, then the range of variation within those classes can be used as a reference baseline to measure outlier distances. Recently, a hydrologic classification of natural flow regimes was completed for the 
entire US (Figure 1, McManamay et al., 2014). Each of the 1180 dam-regulated gauges were assigned to 1 of 15 classes based on climate and landscape variables in random forest models (80\% accuracy) (McManamay et al., 2014). Using the 35 indices summarized for reference and regulated gauges, Mahalanobis distances (D) were calculated as the multivariate distance from each regulated gauge to the centroid of that gauge's respective hydrologic class (McManamay et al., 2014). Hence D is a measure of how far removed a regulated gauge is from natural flow conditions. Prior to calculating D, all magnitude-related variables were standardized by mean daily flow to remove any effects of river size.

\subsection{Assembling a predictor dataset}

Predictors for gauges were placed into four categories: 1) hydroclimatic context, 2) local dam variables, 3) cumulative dam variables, and 4) other disturbance variables (Table 2). Hydrologic responses to dam regulation may vary within different hydroclimatic contexts (Poff et al., 2007; McManamay et al., 2012). Hydrologic classes provide an indication of groups of streams with similar natural hydrologic variation and are useful in stratifying hydrologic responses to disturbance (Arthington et al., 2006). As indicated in section 2.2, the most probable hydrologic class was assigned to each regulated gauge (McManamay et al., 2014) and was included as a predictor to control for natural hydrologic variation across regions (Figure 1).

Local dam variables described the nearest upstream dam on the mainstem or largest tributary from each gauge and included dam storage (L.STOR), a binary indication of diversion at the dam (DIV), dam purpose (PURPOSE), and distance from the gauge. Local dam characteristics were obtained from the National Inventory of Dams (NID) (USACE, 2013). Dam storage represented maximum storage capacity as reported in NID. Diversion dams were 
identified using comments in ADR reports, including "diversion", "bypass", "transbasin transfer", using gauge names (e.g., Gauge 12137800, Sultan River Below Diversion Dam Near Sultan, WA), and using dam names (e.g., NID-OR00716, South Fork Diversion Dam). NID also provides 11 different purposes for dams and each dam may have multiple purposes. In addition, the order indicates the relative importance of purposes. While an exorbitant number of combinations could be possible, 180 different combinations were present for dams in the present dataset. In order to reduce the combinations into a reasonable number, the magnitude and nature of hydrologic responses were hypothesized for dams based on purposes. Five categories were created to represent different types and degrees of hydrologic disturbance: other $(\mathrm{O})$, water supply (S), flood control (F), flood control + water supply (FS), hydropower (H), and hydropower + additional purposes (HA). Dams classified as "other" included smaller ponds used for recreation, fish and wildlife, fire protection, or farming. S dams included irrigation and public supply. F dams included navigation lock and dams. HA included any additional purpose besides hydropower because hydropower was presumed to have the largest effect on hydrology relative to size.

For each gauge, a straight-line distance (SLD) upstream to the nearest upstream dam was calculated using the latitude and longitude coordinates for the dam and the gauge. For each gauge, the GAGES II dataset provided average main-stem sinuousity (SINU), which represents a unit-less ratio of total streamline length $(\mathrm{km})$ to straight-line length $(\mathrm{km})$. Thus, total distance upstream (DIST.DAM) could be calculated as SLD*SINU. In many cases, the nearest upstream dam was not classified as a major dam $(>=15 \mathrm{~m}$ in height or storage $>=5,000$ acre feet). Thus, a distance to the nearest major upstream dam (DIST.MDAM) was calculated similar to that for nearest upstream dam. 
Cumulative dam variables included total upstream storage by dam in the river network (N.STOR) and dam density (D.DENS). Total upstream freshwater withdrawals (WITHD), percent irrigated agriculture (IRRIG), urban development land use (DEV), agricultural land use (PLANT), and percent canals (CANAL) were included as non-dam disturbance variables. All cumulative and non-dam disturbance variables were provided by the GAGES II database as summaries in the watershed upstream of every gauge.

All predictor variables were examined for multicollinearity and skewness in their distribution. L.STOR and N.STOR were correlated as was DIST.DAM and DIST.MDAM. In addition, L.STOR and N.STOR were highly skewed and thus, were $\log (\mathrm{x}+1)$ transformed. In model building, local and cumulative dam variables were considered separately and then combined (see next section). In cases of separate analyses, L.STOR and N.STOR were not modified. However, in cases where both variables were used in models, N.STOR was represented as "additional upstream storage" by subtracting L.STOR from N.STOR. Hence, if

only one dam was upstream, then N.STOR would equal 0. DIST.DAM and DIST.MDAM were considered together as local dam variables. In cases where the nearest upstream dam was major, DIST.MDAM was equal to 0 and DIST.DAM was left unmodified. Otherwise, the entire distance to the nearest major dam was used to calculate DIST.MDAM.

\subsection{Model Building}

Generalized linear mixed models (GLMM) were constructed as alternative hypotheses to test the support for hydroclimatic context, local dam variables, cumulative dam variables, nondam disturbance variables in explaining variation in hydrologic response ratios. GLMM models provide an improved approach over traditional statistical models, in that they account for random 
effects while also handling non-normal data (e.g., Poission, binomial, Gamma distributions)

(Bolker et al., 2008). In the present situation, hydrologic responses to dams are measured using stream gauges, which constitute repeated measures within a given hydroclimatic group (especially in situations where multiple gauges are present along the same river system). In addition, GLMMs provide an opportunity to account for structure in hydrologic responses, which may vary according to hydroclimatic context.

The following models were constructed as combinations of variables: 1) local dam only, 2) cumulative dam only, 3) other disturbance only, 4) local + other disturbance, 5) cumulative + other disturbance, 6) local + cumulative, and 7) all variables (full model) (Table 3). Each predictor variable (12 total) was dropped from the full model as single-term deletions to assess the support for individual predictors. To test the importance of hydroclimatic context, hydrologic classes were added as a random grouping effect (i.e., 1|class) within each of the seven models listed above (Table 3). As a comparison, separate models were constructed that included a randomly-generated class as a null model (i.e., 1|null) to ensure model support was not biased by including structural components, i.e. random effects, as opposed to the true improvement in model performance attributed to including hydrologic classes. While hydrologic classes may provide adequate grouping structure, it was also hypothesized that the effects of dam disturbance variables may be dependent upon hydrologic classes as opposed to fixed effects. Hence, hydrologic class was added as a random slope for two sets of models, one set considering L.STOR or N.STOR as random slopes (e.g., L.STOR/class) and the other set considering L.STOR and N.STOR as fixed effects (Table 3). For each model set, L.STOR or N.STOR was accompanied by all other fixed variables except DIST.DAM and DIST.MDAM. These variables 
were excluded to simplify random effect structure because of the likelihood of also being structured by hydrologic class membership.

GLMM models were used to model hydrologic response ratios as Gamma distributions using an identity linkage. Response ratios ranged from -1 to $\gg 1$ and were highly skewed to the right, representing a Gamma distribution. However, negative values and extremities in the distribution prevented model parameter estimates from converging. Thus, ratios were transformed into a distribution more conducive to analysis (constrained Gamma distribution) by placing all values on a scale from 0 to $>1$ using a $\log (x+3)$ transformation. Models were constructed using the lme4 package (Bates et al. 2014) in the R programming environment. Support for alternative models was examined using corrected Akaike's Information Criterion (AICc) to avoid over-parameterization (Burnham and Anderson, 2002, 2004). Lowest AICc values indicate the best model providing the highest explanatory power relative to the number of parameters, i.e. most parsimonious model (Burnham and Anderson, 2002). AIC weights were also used in model averaging to assess support for models, but also relative importance of individual variables. Relative importance for each individual variable was calculated as $\mathrm{W}_{+}(\mathrm{j})$, the sum of AIC weights across models containing each variable j. Fixed effects for variables were compared as T values, which take into account coefficient direction, magnitude, and error. Model performance was examined using $\mathrm{R}^{2}$ values and classification strength, i.e. the ability of models to accurately classify responses as negative or positive.

\subsection{Error assessment}

Three measures were calculated to represent difference aspects of error in predictions for each gauge. Euclidean distances $(E)$ represent a measure of accuracy, i.e. cumulative degree of 
separation between predicted and observed values for all 35 hydrologic metrics. $E$ was

calculated for each gauge as the sum of squared distances between predicted and observed values using the following formula:

$$
E_{j}=\sqrt{\sum_{i}^{n=35}\left(Y_{i j}-\hat{Y}_{i j}\right)^{2}}
$$

where $Y$ and $\hat{Y}$ are the observed and predicted values, respectively, for the $i^{\text {th }}$ hydrologic metric for the $j^{\text {th }}$ stream gauge. E is sufficient for assessing overall distance of outliers; however E may be a poor assessment of precision. For example, predictions, while inaccurate, may still correlate with observed values. Hence, coefficient of determination, $\mathrm{r}^{2}$, can provide an indication of how well predictions fit the data where:

$$
r_{j}=\frac{\sum_{i}^{n=35}\left(Y_{i j}-\bar{Y}_{j}\right)\left(\hat{Y}_{i j}-\overline{\hat{Y}}_{j}\right)}{\sqrt{\sum_{i}^{n=35}\left(Y_{i j}-\bar{Y}_{j}\right)^{2} \sum_{i}^{n=35}\left(\hat{Y}_{i j}-\overline{\hat{Y}}\right)^{2}}}
$$

where $\bar{Y}$ and $\overline{\hat{Y}}$ are the mean values of all observed and predicted hydrologic metrics, respectively, for the $\mathrm{j}^{\text {th }}$ stream gauge. Lastly, classification strength was calculated as the proportion of predicted values for hydrologic metrics sharing the same directionality, positive or negative, as observed responses.

Sources of error in models could be attributed to different contexts, such as particular hydrologic classes, high cumulative dam regulation, or dam purposes. Error metrics were modeled using GLMMs with Gamma distributions for $\mathrm{E}$ and binomial distributions for $\mathrm{r}^{2}$ and classification strength. Full models with hydrologic classes incorporated as a random effect were used as sources of error in models. High cumulative dam storage relative to local dam storage 
could create situations difficult to accurately model; thus, the ratio of local to cumulative dam regulation (LN.Ratio) was added to full models as an additional variable.

\section{Results}

\subsection{Hydrologic response dataset}

Random forest models performed well at predicting pre-dam regulation hydrologic indices (Table 1). Models for 23 indices explained $>90 \%$ variance in the OOB sample (crossvalidation) whereas 7 of the remaining models explained $>80 \%$ variance (Table 1). Low-flow duration (DL16), low-flow frequency (FL1), predictability (TA2), and reversals (RA8) had relatively low variance explained (61-68\%) compared to other models. Performance was poor for models explaining variation in Julian date of annual minimum and maximum (Table 1) and thus, both indices were removed from the remainder of the analysis. NRMSE values were $<1$ for the majority of models.

Although hydrologic response ratios were variable (centralized around 0), many displayed consistent responses. For example, the following metrics tended to show strong decreases: daily CV flow (MA3), mean annual runoff (MA41), low-flow duration (DL16), number of zero-flow days (DL18), high flows of various duration (DH1-DH5), high-flow frequencies (FH1, FH6), and rise/fall rates (RA1, RA3) (Figure 2). Winter and spring monthly flows (MA12-MA16) were centralized around 0 whereas summer and fall flows showed net increases (Figure 2). Low-flow metrics, such as baseflow index (ML17) and longer-duration low flows (DL3-DL5), tended to show increases (Figure 2). 
[Figure 2 here]

\subsection{Hydrologic response models}

Percent variation explained for best models ranged from $10 \%$ to $31 \%$ whereas classification strength ranged from $61 \%$ to $89 \%$ (Appendix 1). $\mathrm{R}^{2}$ values were highest for reversals (RA8), daily CV flow (MA3), and baseflow index (ML17) whereas classification strength was highest for runoff (MA41), high-flow frequency 2 (FH6), and MA3 (Appendix 1). For the majority of hydrologic indices (25/36), full models with single-term deletions and hydrologic class as a random effect (1 | class) had the highest support based on $\mathrm{AIC}_{\mathrm{c}}$ values (Appendix 1, Supplementary Material). Best models for seven of the indices, however, included L.STOR or N.STOR modeled as random slopes according to hydrologic class membership (Appendix 1). This suggests that fixed effects may not be the most suitable for those metrics and the direction of the effects of dam regulation may vary with hydrologic classes. Of the remaining models, three included only local and cumulative dam variables as fixed effects with class as a random effect. For most metrics, full models with no variable deletions were comparable to best models according to AICc weights (Appendix 1, Supplementary Material).

The relative importance of different variables was compared using $\mathrm{W}+(\mathrm{j})$. Models including hydrologic class as a grouping variable had far higher support (larger $\mathrm{W}+(\mathrm{j}))$ than models containing random grouping structure (Figure 3A). On average, models with L.STOR and N.STOR as random slopes according to hydrologic class had higher support than models including L.STOR and N.STOR as fixed effects and hydrologic classes as random intercepts (Figure 3B). Among the 12 individual variables, PURPOSE and DIV had the highest $\mathrm{W}+(\mathrm{j})$ 
values followed by L.STOR and N.STOR (Figure 3C). Local dam and cumulative dam variables had higher relative importance than other disturbance variables (Figure 3C).

[Figure 3 here]

[Figure 4 here]

When considering full models (full $+1 \mid$ class), fixed-effect coefficients for different predictors varied among hydrologic indices (Figure 4, Supplementary Material). For example, DIV tended to increase daily CV (MA3) but decrease all flow magnitudes (Figure 4, Supplementary Material). Likewise, different PURPOSE categories had highly variable effects according to hydrologic indices. Hydropower (H and HA) and supply dams had the strongest effects on hydrology relative to other dam purposes (Figure 4, Supplementary Material). Hydropower dams tended to decrease low-flow duration (DL16) and zero-flow days (DL18), but increased 1-day high flows (DH1), low-flow frequency (FL1), and rate-of-change indices (RA1, RA3, RA8). Supply dams decreased all flow magnitudes, especially low flows and decreased most rate-of-change indices. Both hydropower and FS dams tended to increase low-flows; however, FS dams increased baseflow index (ML17), increased high-flow duration (DH15), and decreased rise rates (RA1) (Figure 4, Supplementary Material). As would be expected, WITHD had negative effects on flow magnitudes, but was the only disturbance variable with positive effects on daily CV (MA3). DEV increased high-flow frequencies (FH1, FH6) and rate of change indices (RA1-8) whereas PLANT had negative effects on those indices (Figure 4, Supplementary Material). IRRIG decreased runoff (MA41), predictability (TA2), and high-flow frequencies (FH1, FH6). L.STOR and N.STOR both had negative effects on daily CV (MA3) and positive effects on low-flow indices, such as baseflow index (ML17) (Figure 4). For many of 
the hydrologic responses, however, L.STOR and N.STOR had opposing effects when considered jointly (recall that when both variables are considered in the same model, N.STOR = Total upstream storage - L.STOR). For example, L.STOR and N.STOR had opposite effects when considering winter and spring monthly flows, but similar effects on summer and fall flows (Figure 5-6). L.STOR had negative effects on high-flow magnitudes, predictability, and rate-ofchange indices, whereas N.STOR had positive effects (Figure 5-6).

[Figure 5 here]

[Figure 6 here]

Models incorporating random slopes for L.STOR and N.STOR suggested that dam regulation may induce hydrologic responses that are different, even opposing, depending on hydrologic class membership (Supplementary Material). For example, under increasing dam storage scenarios, models typically predicted decreases in daily $\mathrm{CV}$ for all classes except the Super-Stable Groundwater (SSGW) class (Figure 7, Supplementary Material). Likewise, highflow frequencies decreased with increasing dam storage for several classes, but increased for others (Figure 7). Class-specific responses seemed to be associated with perennial versus intermittent stream flow types (Figure 7, Supplementary Material). For example, changes in baseflow index, high-flow frequency, and predictability were more noticeable in intermittent than perennial classes.

[Figure 7 here]

\subsection{Error assessment}


Error metrics ranged considerably across stream gauges suggesting that predicting hydrology for some stream gauges may be more difficult others. $E$ ranged from 0.12 to 4.18 (mean=0.64), $\mathrm{r}^{2}$ ranged from 0 to 0.94 (mean=0.40), and classification strength ranged from 0.14 to 1 (mean=0.69). N.STOR, L.STOR, multipurpose flood control and hydropower dams, and IRRIG had significant positive effects on $E$ whereas LN.Ratio, DIST.MDAM, and PLANT had significant negative effects (Figure 8A, Supplementary Material). DIST.MDAM and PLANT had significant positive effects on $\mathrm{r}^{2}$ whereas D.DENS, DIV, other dams, and WITHD had significant negative effects (Figure 8A, Supplementary Material). Only WITHD had significant effects (negative) on classification strength. E was higher for some intermittent-type streams, especially those located in the western US (Figure 8B, Supplementary Material). Late Timing Runoff and Intermittent-Flashy 2 streams had lower $\mathrm{r}^{2}$ relative to other classes. Snowmelt 2 streams, by far, had lower class strength.

[Figure 8 here]

\section{Discussion}

Statistical models were constructed at the scale of the entire conterminous US to provide a predictive tool to quantify and generalize hydrologic responses to dam regulation. The contrasting effects of local and cumulative dam regulation, including the specific effects of dam purpose and diversions, were compared in addition to the importance of providing the context of regional natural flow variation. In addition, the modeling approach presented provided a method to expand sample sizes beyond that of traditional dam-hydrologic-effect analyses. Model performance, however, was relatively poor with the highest models explaining $30 \%$ of the 
variation in hydrologic response ratios. While this was expected for some hydrologic responses (e.g., low-flows), low performance was unexpected for other responses (e.g., 1-day maximum flow). For example, Fitzugh and Vogel (2011) developed regional regressions to model 1-day maximum flows across the US using natural watershed characteristics, dam storage, and population density. The majority of Fitzugh and Vogel's models explained at least $80 \%$ of the variation in 1-day maximum flow whereas similar models in the present study explained only $20 \%$ of the variation. However, one key difference is that the statistical models in the present study predict the direction and magnitude of hydrologic responses to dam regulation, as opposed to predicting raw magnitudes of hydrologic metrics. In contrast to the present study, Fitzugh and Vogel (2011) determined the effect of dam regulation on flood flow by adjusting values for dam storage to 0 and predicting flood flows under "natural" conditions. Similar to Fitzugh and Vogel (2011), random forests explained $91 \%$ of the variation in raw magnitudes of 1-day high flow in unregulated rivers across the US in the present study (Table 1). Thus, there are multiple approaches for estimating hydrologic alterations; however, predicting hydrologic responses to dam regulation with high certainty is difficult.

In contrast, models performed better at classifying the direction of hydrologic responses as negative or positive. This suggests that the directionality of hydrologic responses to dam regulation may be generalizable whereas the magnitude of responses may be poorly generalized. While some consistencies in hydrologic responses were observed, the directionality in many hydrologic responses to dam regulation were not as expected (e.g., low flows), which suggested either two factors: 1) models predicting pre-dam regulation values for hydrologic indices were inaccurate, or 2) the dams in the current analysis represents a broader sample than that typically considered in other contemporary analyses. For example, the current analysis considers many 
small dams, including diversions. In addition, different models revealed opposing effects of local versus cumulative-dam regulation suggesting that hydrologic responses to cumulative dam regulation are complex, and predicting the hydrology downstream of individual dams may be more easy accomplished using statistical approaches than predicting that of cumulative dam regulation (Poff et al., 1997; Gao et al., 2009). In addition, the responses of some hydrologic indices to dam regulation were highly dependent upon context, such as hydrologic class membership and the purpose of the dam. For instance, multipurpose dams with high storage, high cumulative storage relative to local storage, diversions, and close proximity to dams are all sources of increased error in models. Furthermore, predicting hydrologic responses to dam regulation seems to be more uncertain in some hydrologic classes, such as Late Timing Runoff and Snowmelt 2 streams. Statistical models, such as the ones presented herein, show promise in their ability to generalize the directionality of hydrologic responses to dam regulation. However, great care should be used when using models to predict hydrologic alteration as quantitative estimates given uncertainty in parameters.

\subsection{Hydrologic responses}

One benefit of developing models to predict natural hydrology is that natural hydrologic baseline information can be provided for basins lacking adequate pre-disturbance information. In addition, natural hydrologic models can boost sample sizes for modeling efforts assessing hydrologic alterations across large spatial scales (e.g., Carlisle et al., 2011, Eng et al., 2012). In the current study, sufficient pre-dam disturbance information was only available for 237 gauges, roughly $20 \%$ of the final sample size (1180 gauges). The majority of these gauges were 
downstream and proximate to major dams, constituting a limited sample of regulated gauges induced by dams of various sizes and purposes. Hence, natural hydrologic models provided an opportunity to increase sample size to assess a wider range of hydrologic effects induced by dam-regulation.

Developing statistical models to predict natural hydrology for the purpose of extrapolating values to ungauged or disturbance-prone basins has been increasingly documented in the literature (Sanborn and Bledsoe, 2006; Castellarin et al., 2007; Zhu and Day, 2009; Carlisle et al., 2010; Murphy et al., 2013). Murphy et al. (2013) found that regional regression models, developed using climate and landscape information, performed better than a prevailing rainfall-runoff model in explaining hydrologic statistics (TOPMODEL). Likewise, Zhu and Day (2009) developed regression models (also using climate and landscape information) for predicting baseflow hydrologic statistics, with the majority of $R^{2}$ values $>0.98$. Random forests have been shown to perform well at predicting hydrologic statistics at regional or national scales (Carlisle et al., 2010). Using climate, landscape, geology, and soil information, Carlisle et al. (2010) developed random forest models to predict pre-disturbance values of 13 hydrologic metrics. Reported RMSE values were very similar to the current study and suggested that random forests are a robust modeling framework to predict hydrologic indices under natural conditions.

Many hydrologic responses to dam regulation were consistent with that reported from other studies. In general, variability, high flows, and rise/fall rates showed net decreases whereas low flows and reversals showed net increases as found in other studies (Magilligan and Nislow, 2001, 2005; Maingi and Marsh, 2002; Nislow et al., 2002; Batalla et al., 2004; Pyron and Neumann, 2008; Fitzuh and Vogel, 2011). However, responses in seasonal magnitudes were 
highly variable as documented by others (Richhter et al., 1996; Batalla et al., 2004; Magilligan and Nislow, 2005; Pyron and Neumann, 2008). Winter and spring flows displayed little general patterns in directionality; however, summer and fall flows typically displayed net increases. Specifically, August and September flows correspond to the lowest flow periods throughout the majority of the US; thus, net increases in flow magnitudes during these months is in agreement with multiple studies. Because of differences in timing and magnitude of precipitation and snowmelt, the seasonal timing of high flow events is much more variable across the US than low flows (Poff, 1996). Annual maxima can typically occur between January and June for the majority of the country; thus, the lack of consistent responses by winter and spring flows is not surprising.

Responses by high-flow frequencies are less frequently documented and displayed net decreases post-dam regulation. Decreases in intermittency were also prevalent, suggesting that dam regulation tends to convert intermittent streams to perennial types as suggested by others (Larned et al., 2010; Steward et al., 2012). Dams capture runoff during episodic, high-flow events (Fitzuh and Vogel, 2011), which potentially stabilizes flashy systems (Larned et al., 2010; Steward et al., 2012). However, other studies evaluating anthropogenic-induced hydrologic alterations to intermittent streams have typically noted amplified intermittency through groundwater extractions or diversions at dams (Stromberg et al., 2007; Levick et al., 2008). For example, Stromberg et al. (2007) suggested many perennial stretches of rivers in the arid Southwestern US were becoming increasingly intermittent due to diversions from dams and led to alterations in riparian vegetation community structure.

Despite some consistencies in the net directionality of many variables, most hydrologic response variables had widely varying distributions. For example, increases in low flows were 
not as dramatic and consistent as hypothesized based on previous studies. In many cases, the effects of dam storage on low-flows (DL1-DL5) were negative, opposite as expected. This could have resulted for multiple reasons. First, as opposed to high-flows, low-flows of various duration are difficult to model (Zhu and Day, 2009) because of the contribution of groundwater and the complication of localized soil conditions (Sophocleous and Perkins, 2000). NRMSE values for DL1-DL5 models were typically higher than other models (Table 1) suggesting uncertainty in modeling natural low-flow baseline hydrology. Likewise, Eng et al. (2012) reported that models predicting the probability of inflated flow magnitudes from anthropogenic disturbances performed more poorly than models predicting deflated flows. Secondly, the sample of gauges presented in this analysis represents a wider range of dam regulation (e.g., diversion scenarios) than is typically included in studies assessing wide-spread hydrologic responses to dam regulation (e.g., Poff et al., 2007; Gao et al., 2009). Smaller dams used to divert water for irrigation or hydropower production were included in the current study as opposed to focusing on only large dams. In addition, evaporative losses from reservoirs, on average, account for 5\% of global river flows (Shiklomanov, 2000), but have been reported in excess of $26 \%$ of inflows (Vörösmarty and Sahagian, 2000). The large sample size in this study also increased the likelihood that other factors besides dam regulation, such as withdrawals and urbanization, may have contributed to decreases in low-flows. Because random forests predict natural hydrologic conditions (i.e., pre-disturbance), any disturbances occurring post-dam regulation could have influenced hydrologic responses further highlighting the necessity of including non-dam disturbance variables in models.

\subsection{Response Models}




\subsubsection{Hydrologic classes- Models incorporating hydrologic classes as structural components}

had higher support than alternative models without any structure, which suggests that the response of streams to dam regulation may differ depending on natural hydrologic contexts (McManamay et al., 2012). For example, the results suggested that an intermittent system in the Mid-western US may respond quite differently to dam regulation than a stable, high baseflow system in the Southeastern US. In addition, hydrologic classes may provide an adequate alternative for controlling for background natural hydrologic variation compared to incorporating a suite of predictors of natural streamflow variation (e.g., climate, landscape factors, etc), since hydrologic classes have been predicted with high accuracy using these metrics. Hydrologic classes, when incorporated as random slopes for L.STOR and N.STOR, had higher model support than models incorporating classes as random intercepts. This suggests that the direction of changes in hydrologic variables with increasing dam regulation may vary depending on natural hydrologic baselines. For example, Super-Stable Groundwater (SSGW) systems showed increases in daily $\mathrm{CV}$ with increases in dam storage, whereas all other classes showed consistent decreases (Figure 7). As the name would suggest, SSGW streams are highly stable and lack the high and low extremities found in other classes (McManamay et al., 2014). While dam regulation moderates the extremities in other class types, it creates abnormally higher variation in SSGW streams. As another example, many intermittent stream types displayed increases in predictability with increasing dam storage whereas perennial types displayed decreases (Figure 8). In addition, baseflow index displayed dramatic increases for intermittent classes but moderate increases or decreases in other classes.

4.2.2 Local and Cumulative Dam Regulation - Local dam variables had higher model support than cumulative dam variables. In part, this was because local-dam variables outnumbered and 
tended to be more descriptive of dam operations than cumulative dam variables. However, this potentially also suggests one or a combination of several possible conclusions: 1) generally, the most immediate upstream dam, if large, has the greatest influence on hydrology relative to cumulative upstream disturbance, 2) hydrologic responses to the most immediate upstream dam can be isolated from the effects of cumulative regulation using statistical models, and/or 3) the hydrologic effects of cumulative regulation may be more uncertain and variable and hence, explaining less variation in models.

Among dam-related variables, dam storage has been used the most extensively as an indicator of hydrologic alteration (Vörösmarty and Sahagian, 2000; Nilsson et al., 2005; Lehner et al., 2011). The functional significance of large dams in river systems is storing water, the larger the quantity the larger the downstream hydrologic effect. For instance, increases in dam storage are likely to result in more dramatic decreases in daily variability. Comparisons of local and cumulative storage yielded some unexpected results. When local and cumulative dam storage variables were considered separately in models, their coefficients were similar. However, when both variables were considered jointly, local versus cumulative dam storage had opposing effects for many hydrologic responses (in full models, cumulative storage was adjusted by subtracting local storage). For example, local storage had negative effects on winter-spring flows and low-flows yet the opposite was true for cumulative storage. Local storage and cumulative dam storage were unrelated to each other and to other variables, including dam density, removing the likelihood of false conclusions arising due to multicollinearity. In addition, drainage area was experimentally added to models to determine if cumulative storage was acting as a surrogate effect for larger basins; however, drainage area was not correlated with dam-regulation variables, did not noticeably improve model performance, and did not alter dam 
storage coefficients. Thus, the contrasting effects of local versus cumulative effects are likely the result of 1) higher uncertainty and variability when predicting the effects of cumulative dam regulation or 2) a true mechanistic association as opposed to a spurious finding. As documented elsewhere (Zhang and Wei, 2012), individual anthropogenic activities may offset, rather than compound, the effects of other anthropogenic activities in basins experiencing intensified cumulative disturbance. The model results suggest that extensive upstream dam regulation may stabilize or counter the effects of local dam regulation for many aspects of hydrology. For other hydrologic variables, such as daily variation, baseflow index, and summer/fall flows, the effects of local and cumulative storage may have compounding effects. However, isolating the anthropogenic disturbance responsible for specific hydrologic alterations in basins receiving cumulative disturbance is difficult and requires time-series analysis (Vogl and Lopes, 2009; Zhang and Wei, 2012), well beyond the scope of this paper.

4.2.3 Dam Purpose - Dam purpose and diversions had the highest support in models, which suggests that models need to explicitly account for these two factors in order to ensure accuracy in predicting hydrologic alterations. According to Poff and Hart (2002), one of the biggest challenges in understanding ecological responses (and hydrologic responses) to dams is the absence of a simplified classification system, created on the basis of dam size, purpose, and operation. However, developing a dichotomous classification system is limited by varying classification criteria, such as those used to define operation regimes (e.g., run-of-river, storage, etc), but also the coarse and complex nature of one-to-many purposes provided for each dam. For example, the National Inventory of Dams (NID) lists 11 different purposes for dams, many of which have multiple purposes and the order of which indicates the relative importance. In the entire NID dataset (>87,000 dams), there are 760 different combinations of dam purposes listed, 
180 of which were present in the current dataset. Hence, utilizing the current list of purposes to model hydrologic responses was impractical and required reclassification into larger and coarser groups, but also prioritization of which purposes induce the largest hydrologic effects. Despite the coarseness of the five broad classes of dam purposes generated from the NID database, model results suggested that dam operations (and hence, hydrologic responses) are strongly linked to purposes assigned for each dam. This suggests there is promise and reliability in classifying dams by their purpose to inform changes in hydrology without relying on inflow and outflow data to create dam operation rules (e.g., Hanasaki et al., 2006; Zhang et al., 2010, 2011).

Dams can be placed into two coarse functional categories, storage dams and run-of-river dams (Poff and Hart, 2002). Storage dams typically have the largest effects on hydrology by storing large quantities of water in order to moderate high flows or generate electricity. In contrast, run-of-river dams store lower quantities of water and downstream discharge approximates inflows. In general, storage dams include flood control and hydropower facilities whereas run-of-river dams include water supply and other purposes; however, the function of dams also depends on storage capacity and may not neatly follow these coarse classifications. For example, a large portion of hydropower dams in the US are actually operated as run-of-river facilities with less noticeable influences on hydrology (McManamay and Bevelhimer, 2013). As expected, flood control and hydropower dams had the largest effects on hydrologic responses relative to other purposes. In order to moderate peak flows, flood control dams abnormally increase baseflows and change seasonal timing (Petts et al., 1984); thus, the consistent negative effects of flood-control dams on high flow metrics made intuitive sense. However, most dams, regardless of size or purpose, moderate peak flows (Fergus, 1997; Fitzugh and Vogel, 2011), with decreases becoming more extensive as dam storage increases. Thus, the positive effect of 
hydropower dams on 1-day high flows was somewhat surprising. This does not suggest, however, that hydropower dams have net positive effects on peak flows, but rather, hydropower dams have more neutral effects than other types of dams. Dams with the sole purpose of generating electricity (typically small, run-of-river facilities) had relatively neutral effects on 1day high flows (median, $-9 \%$; average, 10\%) whereas multi-purpose dams that generate electricity (HA) had negative effects on 1-day high flow (median, $-22 \%$, average $-5 \%$ ). In addition to peak flow magnitudes, hydropower dams consistently had opposite effects on hydrology compared to other purposes, including increases in high-flow frequency 1 , rise rates, and fall rates. Unlike other dam regulation, hydropower influences flow on shorter temporal scales (hours to days) through peaking, i.e. discharging high flows to generate electricity (Cushman et al., 1985). These rapid fluctuations in flow may lead to unpredictable changes in daily averages and thus, may more appropriately captured as metrics summarized as within-day variation (Bevelhimer et al., 2014).

4.2.4 Diversions - A general rule of thumb is that large dams decrease variability, increase predictability, and increase low-flows (Poff et al., 2007). While flow-stabilization is typical of larger facilities, water supply dams and diversion dams tended to have just the opposite effects (Stromberg et al. 2007; Levick et al., 2008). Diversion dams typically decrease baseflows but have minimal impacts on peak flow events. This exaggerates the differences between high and low extremities in the hydrograph, leading to harsh disturbance conditions for biota (McManamay et al., 2013). Many studies have noted the complex hydrologic and geomorphic effects of de-watering stream channels, which also lead to many unforeseen indirect habitat changes (Ryan, 1997; Trush et al., 2000; Baker et al., 2011). Thus, when generalizing the fluvial responses of stream hydrology and geomorpohology to dam-regulation, unique effects of 
diversion dams are typically not considered (Grant, 2012), potentially because they may be considered unique or less-common compared to dams with integral powerhouses. However, the occurrence of diversion dams is quite common. Within the US, approximately $40 \%$ of hydropower dams are estimated to divert water around river reaches to generate electricity at downstream power plants (Jager and McManamay, 2014); however, over 1/3 of these dams have dewatered reaches less than $500 \mathrm{~m}$. Globally, however, it is estimated that over $80 \%$ of small hydropower dams ( $<50 \mathrm{MW})$ involve diversions (Kibler and Tullos, 2014). While information on dam purpose is provided in the NID, no easily-accessible database provides information on diversions. Furthermore, the presence/absence of diversions is not synonymous with dam purpose. Isolating the occurrence of diversions is essential for predicting hydrologic responses to dam regulation.

\subsection{Sources of Error in Predicting Hydrologic Alteration}

The considerable range of values in error metrics suggested that hydrologic responses to dam regulation can be predicted with some confidence within particular contexts. However, situations of high cumulative dam storage relative to local dam storage, large multipurpose dams or small supply/recreation dams, and diversions create conditions in which statistical models are poorly suited for providing quantitative estimates of hydrologic changes. In these situations, predicting the directionality in hydrologic responses, as opposed to the magnitude of responses, may be a more suitable alternative. Likewise, predicted responses also varied considerably across hydrologic classes. In general, hydrology responded predictably to dam regulation in stable-perennial type classes whereas hydrologic responses in intermittent-type classes seemed more difficult to predict. However, Late Timing Runoff and Snowmelt 2 streams were the most error-prone, which is likely an artifact that streams in these classes were not regionally 
homogenous but scattered in multiple geographic areas (McManamay et al., 2014); thus, these classes had higher variation among streams than other classes.

Increases in error as a result of high cumulative dam regulation was expected since multiple upstream dams may have very different purposes and hence, operations. For example, the Smith River, VA at USGS gauge 02072000 is primarily regulated by Philpott Dam with little additional upstream regulation (LN.Ratio=0.999). Predicted values for most metrics mirrored observed values (Figure 9). In contrast, the Roanoke River, NC (USGS 02080500) is regulated by Roanoke Rapids Dam in addition to at least 42 major dams upstream (LN.Ratio=0.289) (Figure 9). In this situation, model performance was poor, possibly for a number of reasons. Although many of the dams in the Roanoke are used for hydropower, most are multipurpose facilities, including John H. Kerr Dam, which is used for hydropower, recreation, storage, and flood-control. In addition, operations at Smith Mountain Dam and Leesville Lake Dam, located further upstream, are coordinated as a pumped storage project (AEP 2014), which creates an additional level of complexity in predicting hydrology downstream. Despite having lower storage than other upstream dams, Roanoke Rapids Dam has received the most pressure to reregulate the effects of cumulative upstream dams in order to improve environmental conditions (Rulifson and Manooch, 1990; Richter et al., 1996; Pearsall et al., 2005), given its position as the last facility before Albermarle Sound. Due to considerable flow restoration efforts, hydrology below Roanoke Rapids Dam may resemble more natural than regulated flows; hence, making conditions difficult to predict.

[Figure 9 here] 
Stream gauges regulated by a single-predominant upstream dam does not necessarily translate into accurate or precise model predictions. As an example, stream gauges with high LN.Ratios had variable accuracy, precision, and classification strength values, even within similar hydrologic classes (Figure 10). This suggests specific contexts create conditions difficult to model. For example, the NF Solomon River (USGS 06871800) is completely regulated by Kirwin Reservoir, a flood-control and water supply impoundment, and has an LN.Ratio of 0.997. However, the NF Solomon River was classified as a Late-Timing Runoff system, which is a group of streams characterized by perennial but unpredictable flows with high variation in the timing of high flow events and high numbers of reversals (McManamay et al., 2014). Predicting the responses to dam regulation is difficult in these systems because natural hydrologic patterns are similar to the general effects of dam regulation. As another example, the Snake River (USGS 13077000) is regulated by American Falls reservoir in addition to 16 other major dams upstream (LN.Ratio=0.700). However, precision and classification strength of predicted responses were high (Figure 10).

[Figure 10 here]

\section{Conclusions}

A statistical modelling framework was presented as a predictive tool to quantify and generalize hydrologic responses to dam regulation while taking into account local and cumulative dam regulation, dam purposes, and regional flow variation. Although model performance was poor in making quantitative predictions, models were sufficient at classifying the direction of hydrologic responses as negative or positive. An important contribution of this study is the methodology of model development that includes deriving complex predictors, such 
as dam purpose, and incorporating multi-level hierarchical structure, such as regionally-specific hydrologic responses. More research is needed to develop models able to quantify hydrologic responses to disturbances at large scales, especially disturbances that are complex and sensitive to particular contexts.

Because less than $10 \%$ of dams within the US are considered large (USACE, 2013), modeling frameworks that expand the sample sizes beyond traditional pre- and post-data analyses are needed.. Pre-dam regulation hydrologic records are typically only available for gauges downstream of large dams; thus, analyses relying on pre-post information may only provide a small sub-set of stream gauges regulated by dams. Likewise, analyses that exclude stream gauges experiencing high cumulative dam regulation may also limit conclusions drawn from these observations. The results suggest that regulation by a single proximate upstream dam does not necessarily translate into higher model performance in predicting downstream hydrology.

Predicting hydrologic alteration is important for extending findings for gaged stream reaches to ungauged reaches (Eng et al. 2012). Given that discharge measurements are provided for only a small subset of streams (DeWeber et al. 2014) and biological data are collected in many ungauged basins (USGS 2014), models predicting hydrologic alteration are important for augmenting analyses evaluating ecological responses to altered stream flow regimes (Eng et al. 2012). In addition, areas experiencing rapid basin-wide dam development (Grumbine and Pandit, 2013), predicting hydrologic responses to dam development prior to construction can be highly useful for environmental impact assessments and basin planning. The statistical modeling framework presented can aid in providing information for site-specific assessments of hydrologic 
responses to dam regulation, such as providing a priori estimates of parameters for reservoir operation algorithms in process-based models.

\section{Acknowledgements}

This research was funded by the US Department of Energy’s (DOE) Office of Energy Efficiency and Renewable Energy, Wind and Water Power Program. Oak Ridge National Laboratory is managed by UT-Battelle, LLC, for the DOE under contract DE-AC05-00OR22725. Special thanks to Sujithkumar Surendran Nair for providing comments and editorial suggestions on an earlier version of this manuscript.

\section{References}

Arnold, J.G., Fohrer, N. 2005. SWAT2000: current capabilities and research opportunities in applied watershed modelling. Hydrological Processes 19: 563-572.

Arthington, A.H., Bunn, S.E., Poff, N.L., Naiman, R.J. 2006. The challenge of providing environmental flow rules to sustain river ecosystems. Ecological Applications 16: 13111318.

Baker, D.W., Bledsoe, B.P., Albano, C.M., Poff, N.L. 2011. Downstream effects of diversion dams on sediment and hydraulic conditions of Rocky Mountain streams. RiverResearch and Applications 27: 388-401 
Batalla, R.J., Gómez, C.M., Kondolf, G.M. 2004. Reservoir-induced hydrological changes in the Ebro River basin (NE Spain). Journal of Hydrology 290: 117-136

Bates, D., Maechler, M., Bolker, B., Walker, S., Christensen, R.H.B., Singmann, H. 2014. 1me4: Linear mixed-effects models using Eigen and S4. CRAN R package. Accessed 25 March 2014 at: http://cran.r-project.org/web/packages/lme4/index.html

Bolker, B.M., Brooks, M.E., Clark, C.J., Geange, S.W., Poulsen, J.R., Stevens, M.H.H, White, JS. S. 2008. Generalized linear mixed models: a practical guide for ecology and evolution. Trends in Ecology and Evolution 24: 127 - 135.

Bouraoui, F., Benabdallah S., Jrad A., Bidoglio., G. 2004. Application of the SWAT model on the Medjerda river basin (Tunisia). Physics and Chemistry of the Earth 30: 497-507.

Breiman L. 2001. Random forests. Machine Learning 45: 5-32.

Burnham, K.P., Anderson, D.R. 2002. Model Selection and Multimodel Inference: A Practical Information-Theoretic Approach, 2nd ed., Springer, New York.

Burnham, K. P., Anderson, D. R. 2004. Multimodel inference: understanding AIC and BIC in Model Selection. Sociological Methods and Research 33: 261-304.

Carlisle, D.M., Falcone, J., Wolock, D.M., Meador, M.R., Norris, R.H. 2010.Predicting the natural flow regime: models for assessing hydrological alteration in streams. River Research and Applications 26: 118-136.

Carlisle, D.M., Wolock, D.M., Meador, M.R. 2011. Alteration of streamflow magnitudes and potential ecological consequences: a multiregional assessment. Frontiers in Ecology and the Environment 9: 264-270.

Castellarin A., Camorani, G., Brath, A.2007. Predicting annual and long-term flow-duration curves in ungauged basins. Advances in Water Resources 30: 937-953 
Cushman, R.M. 1985. Review of ecological effects of rapidly varying flows downstream from hydroelectric facilities. North American Journal of Fisheries Management 5: 330 - 339.

Cutler, D.R., Edwards, T.C., Beard, K.H., Cutler, A., Hess, K.T., Gibson, J., Lawler, J.J. 2007. Random forests for classification in ecology. Ecology 88: 2783-2792.

DeWeber, J.T., Y-P Tsang, D.M. Krueger, J.B. Whittier, T. Wagner, D.M. Infante, and G. Whelan. 2014. Importance of understanding landscape biases in USGS gage locations: implications and solutions for managers. Fisheries 39: 155-163.

Döll, P., Kasper, F., Lehner, B. 2003. A global hydrological model for deriving water availability indicators: model tuning and validation. Journal of Hydrology 270: 105-134.

Eng K., Carlisle, D.M., Wolock, D.M., Falcone, J.A. 2012. Predicting the likelihood of altered streamflows at ungauged rivers across the conterminous United States. River Research and Applications 29: 781-791.

Falcone, J.A., Carlisle, D.M., Wolock, D.M., Meador, M.R. 2010. GAGES: a stream gage database for evaluating natural and altered flow conditions in the conterminous United States. Ecology 91: 621.

Falcone, J.A. 2011. GAGES-II: geospatial attributes of gages for evaluating streamflow. Accessed 9 November 2011 at: http://water.usgs.gov/GIS/metadata/usgswrd/XML/gagesII_Sept2011.xml\#Identification_ Information

Fergus, T. 1997. Geomorphological response of a river regulated for hydropower: River Fortun, Norway. Regulated Rivers: Research and Management 13: 449-461.

Fitzhugh, T.W., Vogel, R.M. 2011. The impact of dams on flood flows in the United States. River Research and Applications 27: 1192-1215. 
Gao, Y., Vogel, R.M., Kroll, C.N., Poff, N.L., Olden, J.D. 2009. Development of representative indicators of hydrologic alteration. Journal of Hydrology 374: 136-147

Graf, W.L. 2005. Geomorphology and American dams: The scientific, social, and economic context. Geomorphology 71: $3-26$.

Grant, G.E. 2012. The geomorphic response of gravel-bed rivers to dams: perspectives and prospects, in: Church, M., Biron, P.M., Roy, A.G. (Eds.), Gravel-bed rivers: processes, tools, environments. John Wiley \& Sons, New York, pp.165-181.

Grumbine, R.E, Pandit, M.K. 2013. Threats from India's Himalaya dams. Science 339: 36-37.

Haddeland, I., Skaugen, T., Lettenmaier, D.P. 2007. Hydrologic effects of land and water management in North America and Asia: 1700-1992. Hydrology and Earth System Sciences 11: 1035-1045.

Hanasaki, N., Kanae S., Oki T. 2006. A reservoir operation scheme for global river routing models. Journal of Hydrology 327: 22- 41.

Henriksen, J.A., Heasley, J., Kennen, J.G., Niewsand, S. 2006. Users' manual for the hydroecological integrity assessment process software (including the New Jersey Assessment Tools): U.S. Geological Survey, Biological Resources Discipline, Open File Report 2006-1093, 71 pp.

Jager, H. I., McManamay, R.A. 2014. Comment on "Cumulative biophysical impact of small and large hydropower development in Nu River, China'” by Kelly M. Kibler and Desiree D. Tullos. Water Resources Research 50: 758-759,

Kalogeropoulos, K., Chalkias, C., Pissias, E., Karalis, S. 2011. Application of the SWAT model for the investigation of reservoirs creation, in: Lambrakis, N., et al. (Eds.), Advances in 
the Research of Aquatic Environment, Vol. 2, DOI 10.1007/978-3-642-24076-8, Springer-Verlag Berlin Heidelberg, New York.

Kibler, K.M, Tullos, D.D. 2014. Reply to comment by Henriette I. Jager and Ryan A. McManamay on "Cumulative biophysical impact of small and large hydropower development in Nu River, China”. Water Resources Research 50: 760-761.

Labadie, J.W. 2004. Optimal Operation of multireservoir dystems: state-of-the-art review. Journal of Water Resources Planning and Management 130: 93-111.

Larned ST, Datry T, Arscott DB, Tockner K. 2010. Emerging concepts in temporary-river ecology. Freshwater Biology 5: 717-738.

Lehner, B., Lierman, C.R., Revenga, C., Vörösmarty, C., Fekete, B., Crouzet, P., Döll, P., Endejan, M., Frenken, K., Magome, J., Nilsson, C., Robertson, J.C., Rödel, R., Sindorf, N., Wisser, D. 2011. High-resolution mapping of the world's reservoirs and dams for sustainable river-flow management. Front Ecology 9: 494-502.

Levick, L., J. Fonseca, D. Goodrich, M. Hernandez, D. Semmens, J. Stromberg, R. Leidy, M. Scianni, D. P. Guertin, M. Tluczek, and W. Kepner. 2008. The ecological and hydrological significance of ephemeral and intermittent streams in the arid and semi-arid American Southwest. U.S. Environmental Protection Agency and USDA/ARS Southwest Watershed Research Center, EPA/600/R-08/134, ARS/233046.116 pp.

Magilligan, F.J., Nislow, K.H. 2001. Long-term changes in regional hydrologic regime following impoundment in a humid-climate watershed. Journal of the American Water Resources Association 37: 1551-1569.

Magilligan, F.J., Nislow, K.H. 2005. Changes in hydrologic regime by dams. Geomorphology 71: 61-78. 
Maingi, J.K., Marsh, S.E. 2002. Quantifying hydrologic impacts following dam construction along the Tana River, Kenya. Journal of Arid Environments 50: 53-79.

McManamay, R.A., Bevelhimer, M.S. 2013. A holistic framework for environmental flows determination in hydropower contexts. Oak Ridge National Laboratory Technical Manuscript. ORNL/TM-2013/159.

McManamay, R.A., Bevelhimer, M.S., Kao, S. 2014. Updating the US hydrologic classification: an approach to clustering and stratifying ecohydrologic data. Ecohydrology 7: 903-926.

McManamay, R.A., Orth, D.J., Dolloff, C.A. 2012. Revisiting the homogenization of dammed rivers in the Southeastern US. Journal of Hydrology 424-425: 217-237.

McManamay, R.A., Orth, D.J., Dolloff, C.A. 2013. Case Study: Application of the ELOHA framework to regulated rivers in the Upper Tennessee River basin. Environmental Management 51:1210-1235.

Murphy, J.C., Knight, R.R., Wolfe, W.J., Gain, W.S. 2013. Predicting ecological flow regime at ungaged sites: a comparison of methods. River Research and Applications 29: 660-669.

Nilsson, C., Reidy, C.A., Dynesius, M., Revenga, C. 2005. Fragmentation and flow regulation of the World's large river systems. Science 308: 405 - 408.

Nislow, K.H., Magilligan, F.J., Fassnatcht, H., Bechtel, D., Ruesink, A. 2005. Effects of dam impoundment on the flood regime of natural flooplain communities in the upper Connecticut River. Journal of the American Water Resources Association 38: 1533-1548.

Olden, J.D., Poff, N.L. 2003. Redundancy and the choice of hydrologic indices for characterizing streamflow regimes. River Research and Applications 19: 101-121.

ORNL (Oak Ridge National Laboratory). 2014. (NHAAP) National Hydropower Asset Assessment Program. Available at: http://nhaap.ornl.gov/. Accessed 13 June 2013. 
Pearsall, S.H., McCrodden, B.J., Townsend, P.A. 2005. Adaptive management of flows in the lower Roanoke River, North Carolina, USA. Environmental management 35: 353-367.

Petts, G.E. 1984. Impounded rivers: perspectives for ecological management. John Wiley and Sons, New York.

Poff, N.L., Hart, D.D. 2002. How dams vary and why it matters for the emerging science of dam removal. BioScience 52: 660-668.

Poff, N.L., Allan, J.D., Bain, M.B., Karr, J.R., Prestegaard, K.L., Richter, B.D., Sparks, R.E., Stromberg, J.C. 1997. The natural flow regime: a paradigm for river conservation and restoration. BioScience 47: 769-784.

Poff, N.L., Olden, J.D., Merritt, D.M., Pepin, D.M., 2007. Homogenization of regional river dynamics by dams and global biodiversity implications. Proceedings of the National Academy of Sciences 104: 5732-5737.

Poff, N.L., Richter, B.D., Arthington, A.H., Bunn, S.E., Naiman, R.J., Kendy, E., Acreman, M., Apse, C., Bledsoe, B.P., Freeman, M.C., Henriksen, J., Jacobson, R.B., Kennen, J.G., Merritt, D.M., O’Keeffe, J.H., Olden, J.D., Rogers, K., Tharme, R.E., Warner, A. 2010. The ecological limits of hydrologic alteration (ELOHA): a new framework for developing regional environmental flow standards. Freshwater Biology 55, 147-170.

Pyron, M., Neumann, K., 2008. Hydrologic alterations in the Wabash River watershed, USA. River Research and Applications 24: 1175-1184.

Richter, B.D., Baumbartner, J.V., Braun, D.P., Powell, J. 1998. A spatial assessment of hydrologic alteration within a river network. Regulated Rivers: Research and Management 14: 329-340. 
Richhter, B.D., Baumgartner, J.V., Powell, J., Braun, D.P. 1996. A method for assessing hydrologic alteration within ecosystems. Conservation Biology 10: 1163-1174.

Richter, B.D., Baumgartner, J.V., Wiginton, R., Braun, D.P. 1997. How much water does a river need? Freshwater Biology 37: 231-249.

Richter, B.D., Davis, M.M., Apse, C., Konrad, C. 2012. A presumptive standard for environmental flow protection. River Research and Applications 28: 1312-1321.

Rulifson, R.A., Manooch, C.S. 1990. Recruitment of juvenile striped bass in the Roanoke River, North Carolina, as related to reservoir discharge. North American Journal of Fisheries Management 10: 397-407.

Ryan S. 1997. Morphologic responsMce of subalpine streams to transbasin flow diversion. Journal of the American Water Resources Association 33: 839-854.

Sanborn, S.C., Bledsoe, B.P., 2006. Predicting streamflow regime metrics for ungaged streams in Colorado, Washington, and Oregon. Journal of Hydrology 325: 241-261.

Shiklomanov IA. 2000. Appraisal and assessment of world water resources. International Water Resources Association 25: 11-32

Shresha, B.P, Duckstein, 1., Stakhi, E.A. 1996. Fuzzy rule-based modelling of reservoir operation. Journal of Water Resources Planning and Management 122: 262-269.

Sophocleous, M., Perkins, S.P., 2000. Methodology and application of combined watershed and ground-water models in Kansas. Journal of Hydrology 236: 185-201.

Stedinger, J.R., Pei, D., Cohn, T.A. 1985. A condensed disagreegation model for incorporating parameter uncertainty into monthly reservoir simulations. Water Resources Research 21: $665-675$. 
Stedinger, J.R., Sule, B.F., Loucks, D.P. 1985. Stochastic dynamic programming models for reservoir operation optimization. Water Resources Research 20: 1499-1505.

Steward AL, von Schiller D, Tockner K, Marshall JC, Bunn SE. 2012. When the river runs dry: Human and ecological values of dry riverbeds. Frontier in Ecology and Environment 10: 202-209.

Stromberg, J.C., S.J. Lite, R. Marler, C. Paradzick, P.B. Shafroth, D. Shorrock, J.M. White, and M.S. White. 2007. Altered stream-flow regimes and invasive plant species: the Tamarix case. Global Ecology and Biogeography 16: 381-393

Trush, W.J., McBain, S.M., Leopold, L.B. 2000. Attributes of an alluvial river and their relation to water policy and management. Proceedings of the National Academy of Sciences 97: 11858-11863.

USACE (US Army Corps of Engineers), 2013. Corps Map. National Inventory of Dams. US Army Corps of Engineers. Available at: https://nid.usace.army.mil. Accessed 8 July 2013.

USGS (US Geological Survey). 2014. National Water-Quality Assessment (NAWQA) Program. Available at: http://water.usgs.gov/nawqa/. Accessed 30 June 2014.

Vog1, A.L., Lopes, V.L., 2009. Impacts of water resources development on flow regimes in the Brazos River. Environmental Monitoring and Assessment 157: 331-345.

Vörösmarty, C.J., Moore, B. 1991. Modeling basin-scale hydrology in support of physical climate and global biogeochemical studies: an example using the Zambezi River. Surveys in Geophysics 12: 271-311.

Vörösmarty, C.J., Sahagian, D. 2000. Anthropogenic disturbance of the terrestrial water cycle. BioScience 50: 753-765. 
Wurbs, R.A. 1993. Reservoir-system simulation and optimization models. Journal of Water Resources Planning and Management 119: 455-472.

Yeh, W.W-G. 1985. Reservoir management and operations models: a state-of-the-art review. Water Resources Research 21: 1797-1818.

Zhang, M., Wei, X. 2012. The effects of cumulative forest disturbance on streamflow in a large watershed in the central interior of British Columbia, Canada. Hydrologic and Earth Systems Sciences 16: 2021-2034.

Zhang, Y., Xia, J, Liang, T., Shao, Q. 2010. Impact of water projects on river flow regimes and water quality in Huai River Basin. Water Resources Management 24: 889-908.

Zhang, Y., Xia, J., Chen, J., Zhang, M. Water quantity and quality optimization modeling of dams operation based on SWAT in Wenyu River Catchment, China. Environmental Monitoring and Assessment 173: 409-430.

Zhu, Y., Day, R.L. 2009. Regression modeling of streamflow, baseflow, and runoff using geographic information systems. Journal of Environmental Management 90: 946-953.

\section{Figure captions}

Figure 1. Dam-regulated stream gauges assigned to natural hydrologic classes using landscape and climate models (taken and modified from McManamay et al. 2014).

Figure 2. Response ratios for 35 hydrologic metrics calculated from pre- to post-dam regulation as (post - pre)/pre. 
Figure 3. Akaike's Information Criterion weights, $W_{+}(j)$, used to assess the relative importance of alternative models, such as (A) incorporating hydrologic classes as random effects in models as opposed to null random effects, (B) structuring local dam storage (L.STOR) and cumulative dam storage (N.STOR) as random slopes within hydrologic classes as opposed to fixed effects, and (C) comparisons of the importance of all fixed-effect variables in explaining variation in hydrologic responses. Bars depicting fixed-effect variables are shaded according to three groups of variables (local dam, cumulative dam, and other disturbances).

Figure 4. Comparisons of $\mathrm{T}$ statistic values for fixed-effect coefficients in full models for all hydrologic responses. Full models refer to model no. 13 in Table 3. White and black bars represent positive and negative effects, respectively. Black dots indicate statistical significance, $\mathrm{p}<0.05$.

Figure 5. Comparison of T statistics for fixed-effect coefficients for local dam storage (L.STOR) and cumulative dam storage (N.STOR) in predicting hydrologic responses when considered jointly in full models (model no. 13 in Table 3). In joint models, N.STOR = total cumulative upstream storage - L.STOR to avoid effects of multicollinearity. Dashed line indicates $T$ value representing statistical significance, $\mathrm{p}<0.05$.

Figure 6. Comparison of T statistics for fixed-effect coefficients for local dam storage (L.STOR) and cumulative dam storage (N.STOR) when considered separately (model nos. 16 and 18 in Table 3, respectively). In separate models, N.STOR = total cumulative upstream storage including local dam storage. Dashed line indicates T value representing statistical significance, $\mathrm{p}<0.05$. 
Figure 7. Simulated hydrologic responses to increasing local dam storage among different hydrologic classes. Dam storage effects were based on models incorporating local dam storage as random slopes within hydrologic classes. Simulations were conducted by varying local dam storage while keeping other variables constant and were based upon model no. 15 in Table 3.

Figure 8. Assessment of sources of error in hydrologic response models. (A) Comparisons of Tstatistics for fixed-effect coefficients in predicting Euclidean distances, $\mathrm{r}^{2}$, and classification strength. (B) Effects of hydrologic classes on error were assessed by comparing random intercept values.

Figure 9. Comparison of observed versus predicted values for the Smith River, primarily regulated by Philpott Dam, and for the Roanoke River, regulated by Roanoke Rapids Dam in addition to 42 other major dams. Predicted values were based on full models (model no. 13, Table 3).

Figure 10. Comparison of observed versus predicted values for multiple gauges representing a variety of natural hydrologic contexts and regulation contexts: (A) USGS 02072000 Smith River near Philpott, VA, (B) USGS 13077000 Snake River at Neeley ID, (C) USGS 06282000 Shoshone River below Buffalo Bill Reservoir, WY, (D) USGS 02080500 Roanoke River at Roanoke Rapids, NC, (E) USGS 13341050 Clearwater River near Peck ID, (F) USGS 06871800 NF Solomon R at Kirkwin, KS. Gauges A-C represent streams with relatively precise and/or accurate model predictions whereas gauges D-F represent streams where model performance was poor. Predicted values were based on full models (model no. 13, Table 3). 
Table 1. Performance of random forest models in predicting hydrologic indices in referencecondition streams. \% Variation refers to variation explained within the out-of-bag (OOB) sample using a cross-validation procedure. NRMSE refers to RMSE normalized by the range in the data. All indices were $\log (\mathrm{x}+1)$ transformed prior to model construction except for those indicated by $*$. Indices denoted by $\uparrow$ were not included in subsequent analyses because of poor performance in random forests.

\begin{tabular}{|c|c|c|c|c|c|c|}
\hline Group & $\begin{array}{l}\text { Hydrologic } \\
\text { Index }\end{array}$ & Description & $\begin{array}{c}\text { Mean } \\
\text { (log trans.) }\end{array}$ & $\begin{array}{c}\% \text { Var } \\
\text { Explained }\end{array}$ & RMSE & NRMSE \\
\hline Variation & MA3 & Daily CV & 2.240 & 87.16 & 0.219 & 0.095 \\
\hline \multirow[t]{12}{*}{ Monthly Flows } & MA12 & Jan Flow & 1.839 & 93.96 & 0.500 & 0.623 \\
\hline & MA13 & Feb Flow & 1.905 & 93.72 & 0.496 & 0.518 \\
\hline & MA14 & Mar Flow & 2.015 & 93.83 & 0.474 & 0.513 \\
\hline & MA15 & Apr Flow & 2.073 & 93.29 & 0.485 & 0.529 \\
\hline & MA16 & May Flow & 2.061 & 92.38 & 0.516 & 0.586 \\
\hline & MA17 & Jun Flow & 1.938 & 92.08 & 0.530 & 0.537 \\
\hline & MA18 & Jul Flow & 1.713 & 90.77 & 0.552 & 0.670 \\
\hline & MA19 & Aug Flow & 1.556 & 90.34 & 0.552 & 0.619 \\
\hline & MA20 & Sep Flow & 1.543 & 90.89 & 0.539 & 0.606 \\
\hline & MA21 & Oct Flow & 1.595 & 91.92 & 0.513 & 0.750 \\
\hline & MA22 & Nov Flow & 1.714 & 93.28 & 0.499 & 0.829 \\
\hline & MA23 & Dec Flow & 1.794 & 93.99 & 0.492 & 0.884 \\
\hline Runoff & MA41 & Runoff & 0.331 & 92.94 & 0.130 & 0.099 \\
\hline \multirow[t]{8}{*}{ Low Flows } & ML17* & Baseflow Index & 0.134 & 79.1 & 0.071 & 0.078 \\
\hline & DL1 & 1-Day Low & 0.923 & 89.03 & 0.579 & 2.102 \\
\hline & DL2 & 3-Day Low & 0.937 & 89.11 & 0.579 & 2.101 \\
\hline & DL3 & 7-Day Low & 0.961 & 89.43 & 0.573 & 2.075 \\
\hline & DL4 & 30-Day Low & 1.071 & 90.65 & 0.544 & 1.948 \\
\hline & DL5 & 90-Day Low & 1.312 & 92.78 & 0.490 & 1.704 \\
\hline & DL16 & Low-flow Dur & 1.081 & 61.09 & 0.526 & 0.233 \\
\hline & DL18 & Zero-flow Days & 0.432 & 78.16 & 0.809 & 0.316 \\
\hline \multirow[t]{6}{*}{ High Flows } & DH1 & 1-Day High & 3.119 & 91.26 & 0.501 & 0.235 \\
\hline & $\mathrm{DH} 2$ & 3-Day High & 2.970 & 92.04 & 0.479 & 0.276 \\
\hline & DH3 & 7-Day High & 2.809 & 92.43 & 0.464 & 0.335 \\
\hline & $\mathrm{DH} 4$ & 30-Day High & 2.525 & 92.99 & 0.447 & 0.568 \\
\hline & DH5 & 90-Day High & 2.314 & 93.54 & 0.436 & 1.122 \\
\hline & DH15 & High-flow Dur & 1.081 & 82.73 & 0.276 & 0.165 \\
\hline \multirow[t]{2}{*}{ Timing } & $\mathrm{TL} 1 \dagger$ & Date Ann Min & 2.320 & 39.45 & 0.557 & 0.002 \\
\hline & $\mathrm{TH} 1 \uparrow$ & Date Ann Max & 1.917 & 59.41 & 0.554 & 0.002 \\
\hline Predictability & TA2* & Predictability & 57.20 & 68.41 & 8.927 & 0.107 \\
\hline \multirow[t]{3}{*}{ Frequencies } & FL1 & Low-flow Freq & 0.778 & 67.53 & 0.358 & 0.243 \\
\hline & FH1 & High-flow Freq & 0.941 & 86.16 & 0.209 & 0.155 \\
\hline & FH6 & High-flow Freq2 & 0.871 & 86.65 & 0.232 & 0.145 \\
\hline \multirow[t]{3}{*}{ Rate of Change } & RA1 & Rise Rate & 1.693 & 90.5 & 0.502 & 0.214 \\
\hline & RA3 & Fall Rate & 1.415 & 91.21 & 0.431 & 0.183 \\
\hline & RA8 & Reversals & 1.927 & 67.67 & 0.211 & 0.118 \\
\hline
\end{tabular}


Table 2. Predictor variables for hydrologic response models. Effect type includes random effects (RE) as grouping factors and random slopes (RS) within grouping factors.

\begin{tabular}{|c|c|c|c|}
\hline Variable & Unit & Description & $\begin{array}{l}\text { Effect } \\
\text { Type }\end{array}$ \\
\hline \multicolumn{4}{|c|}{ Hydroclimatic Context } \\
\hline Class & Factor & $\begin{array}{l}\text { Hydrologic classification that groups streams } \\
\text { according to similar hydrologic characteristics }\end{array}$ & $\begin{array}{c}\mathrm{RE} \\
\text { (group) }\end{array}$ \\
\hline \multicolumn{4}{|l|}{ Local Dam } \\
\hline L.STOR & $\mathrm{ML} \mathrm{km}^{-2}$ & $\begin{array}{l}\text { Total storage (megaliters }[\mathrm{ML}]) \text { of the nearest } \\
\text { upstream dam corrected for drainage area }(\mathrm{km} 2) \text { of } \\
\text { gauge }\end{array}$ & $\begin{array}{l}\text { Fixed; } \\
\text { RS }\end{array}$ \\
\hline DIV & Binary & $\begin{array}{l}\text { Indication of large amounts of water diverted } \\
\text { upstream including bypasses and transbasin } \\
\text { transfers }\end{array}$ & Fixed \\
\hline PURPOSE & Factor & $\begin{array}{l}\text { Classificaton of dams by their purpose (from NID } \\
\text { 2013). Purposes included: other (O), water supply } \\
\text { (S), flood control (F), flood control + water supply } \\
\text { (FS), hydropower (H), and hydropower + } \\
\text { additional purposes (HA). }\end{array}$ & Fixed \\
\hline DIST.DAM & $\mathrm{km}$ & River distance to nearest upstream dam & Fixed \\
\hline DIST.MDAM & $\mathrm{km}$ & $\begin{array}{l}\text { River distance to nearest upstream major dam (if } \\
\text { same as DIST.DAM, then value =0). }\end{array}$ & Fixed \\
\hline \multicolumn{4}{|c|}{ Cumulative Dam } \\
\hline N.STOR & $\mathrm{ML} \mathrm{km}^{-2}$ & $\begin{array}{l}\text { Total storage (megaliters }[\mathrm{ML}]) \text { of all upstream } \\
\text { dams corrected for drainage area }(\mathrm{km} 2) \text { of gauge. } \\
\text { When considered with L.STOR, N.STOR was } \\
\text { recalculated as N.STOR - L.STOR }\end{array}$ & $\begin{array}{l}\text { Fixed; } \\
\text { RS }\end{array}$ \\
\hline D.DENS & $\begin{array}{c}\text { dams } \\
\mathrm{km}^{-2}\end{array}$ & $\begin{array}{l}\text { Total number of dams upstream of each gauge per } \\
100 \mathrm{~km} 2 \text { of drainage area }\end{array}$ & Fixed \\
\hline \multicolumn{4}{|c|}{ Other Disturbance } \\
\hline WITHD & ML $\mathrm{yr}^{-1} \mathrm{~km}^{-2}$ & $\begin{array}{l}\text { Total upstream freshwater withdrawals (megaliters } \\
{[\mathrm{ML}] \text { ) per } \mathrm{km} 2}\end{array}$ & Fixed \\
\hline IRRIG & $\%$ & Percent of irrigated lands in upstream watershed & Fixed \\
\hline $\mathrm{DEV}$ & $\%$ & $\begin{array}{l}\text { Percent of low, medium, and high intensity } \\
\text { developed lands in upstream watershed }\end{array}$ & Fixed \\
\hline PLANT & $\%$ & $\begin{array}{l}\text { Percent of planted or cultivated lands in upstream } \\
\text { watershed }\end{array}$ & Fixed \\
\hline CANALS & $\%$ & $\begin{array}{l}\text { Percent of total stream length in upstream } \\
\text { watershed classified as "canal", "ditch" or } \\
\text { "pipeline" }\end{array}$ & Fixed \\
\hline
\end{tabular}


Table 3. Alternative models to predict hydrologic responses. All models were applied to each hydrologic response variable. In addition to models listed, each predictor (12 total) was dropped from the Full Model (no. 13) as single-term deletions to assess support for individual variables. $(\mathrm{HC})=$ hydrologic classes as random effect.

\begin{tabular}{|c|c|c|}
\hline Alternative Models & Fixed Effects & Random Effect \\
\hline 1. Local Dam (HC) & $\begin{array}{l}\text { L.STOR, DIST.DAM, DIST.MDAM, DIV, } \\
\text { PURPOSE }\end{array}$ & $(1 \mid$ class $)$ \\
\hline 2. Local Dam & $\begin{array}{l}\text { L.STOR, DIST.DAM, DIST.MDAM, DIV, } \\
\text { PURPOSE }\end{array}$ & (1| null) \\
\hline 3. CumDam (HC) & N.STOR, D.DENS & (1 | class) \\
\hline 4. Cum Dam & N.STOR, D.DENS & (1| null) \\
\hline 5. Other Disturb (HC) & $\begin{array}{l}\text { FW.WITHD, PCT_IRRIG, DEV, PLANT, } \\
\text { CANALS }\end{array}$ & $(1 \mid$ class $)$ \\
\hline 6. Other Disturb & $\begin{array}{l}\text { FW.WITHD, PCT_IRRIG, DEV, PLANT, } \\
\text { CANALS }\end{array}$ & (1 $\mid$ null) \\
\hline 7. Local Dam + Cum Dam (HC) & $\begin{array}{l}\text { L.STOR, DIST.DAM, DIST.MDAM, DIV, } \\
\text { PURPOSE, N.STOR, D.DENS }\end{array}$ & $(1 \mid$ class $)$ \\
\hline 8. Local Dam + Cum Dam & $\begin{array}{l}\text { L.STOR, DIST.DAM, DIST.MDAM, DIV, } \\
\text { PURPOSE, N.STOR, D.DENS }\end{array}$ & (1 $\mid$ null $)$ \\
\hline 9. Local Dam + Other Disturb (HC) & $\begin{array}{l}\text { L.STOR, DIST.DAM, DIST.MDAM, DIV, } \\
\text { PURPOSE, FW.WITHD, PCT_IRRIG, DEV, } \\
\text { PLANT, CANALS }\end{array}$ & $(1 \mid$ class $)$ \\
\hline 10. Local Dam + Other Disturb & $\begin{array}{l}\text { L.STOR, DIST.DAM, DIST.MDAM, DIV, } \\
\text { PURPOSE, FW.WITHD, PCT_IRRIG, DEV, } \\
\text { PLANT, CANALS }\end{array}$ & (1| null) \\
\hline 11. Cum Dam + Other Disturb $(H C)$ & $\begin{array}{l}\text { N.STOR, D.DENS, FW.WITHD, } \\
\text { PCT_IRRIG, DEV, PLANT, CANALS }\end{array}$ & $(1 \mid$ class $)$ \\
\hline 12. Cum Dam + Other Disturb & $\begin{array}{l}\text { N.STOR, D.DENS, FW.WITHD, } \\
\text { PCT_IRRIG, DEV, PLANT, CANALS }\end{array}$ & (1 null) \\
\hline 13. Full Model (HC) & all variables above & $(1 \mid$ class $)$ \\
\hline 14. Full Model & all variables above & (1 $\mid$ null) \\
\hline 15. Local Storage random slope & $\begin{array}{l}\text { DIV, PURPOSE, FW.WITHD, PCT_IRRIG, } \\
\text { DEV, PLANT, CANALS }\end{array}$ & (L.STOR | class) \\
\hline 16. Local Storage random group & $\begin{array}{l}\text { L.STOR, DIV, PURPOSE, FW.WITHD, } \\
\text { PCT_IRRIG, DEV, PLANT, CANALS }\end{array}$ & $(1 \mid$ class $)$ \\
\hline 17. Network Storage random slope & $\begin{array}{l}\text { DIV, PURPOSE, FW.WITHD, PCT_IRRIG, } \\
\text { DEV, PLANT, CANALS }\end{array}$ & (N.STOR | class) \\
\hline 18. Network storage random group & $\begin{array}{l}\text { N.STOR, DIV, PURPOSE, FW.WITHD, } \\
\text { PCT_IRRIG, DEV, PLANT, CANALS }\end{array}$ & $(1 \mid$ class $)$ \\
\hline
\end{tabular}


Appendix 1. Comparison of support for best models and full models for each hydrologic response index using corrected Akaike's Information Criterion $\left(\mathrm{AIC}_{\mathrm{c}}\right)$ weights. $\mathrm{R}^{2}$ is provided as $\%$ variance explained. Class refers to the accuracy in classifying responses as negative or positive.

\begin{tabular}{|c|c|c|c|c|}
\hline $\begin{array}{l}\text { Hydrologic } \\
\text { Index }\end{array}$ & Best Model & $\mathrm{AIC}_{\mathrm{c}} \mathrm{Wt}$. & $\mathrm{R}^{2}$ & Class \\
\hline \multirow{2}{*}{ MA3 } & (N.STOR | class) + DIV + PURPOSE + Other Dist & 0.989 & 0.29 & 0.81 \\
\hline & Full Model + (1 | class $)$ & 0.001 & 0.28 & 0.81 \\
\hline \multirow{2}{*}{ MA12 } & Full Model $+(1 \mid$ class $)$ - DIST.DAM & 0.416 & 0.19 & 0.63 \\
\hline & Full Model + (1 | class $)$ & 0.154 & 0.19 & 0.63 \\
\hline \multirow[t]{2}{*}{ MA13 } & Full Model $+(1 \mid$ class $)-$ CANALS & 0.443 & 0.18 & 0.65 \\
\hline & Full Model + (1| class $)$ & 0.199 & 0.18 & 0.65 \\
\hline \multirow[t]{2}{*}{ MA14 } & Full Model + $(1 \mid$ class $)-$ WITHD & 0.346 & 0.21 & 0.61 \\
\hline & Full Model + (1| class $)$ & 0.172 & 0.21 & 0.60 \\
\hline \multirow[t]{2}{*}{ MA15 } & Full Model $+(1 \mid$ class $)-$ DEV & 0.359 & 0.18 & 0.64 \\
\hline & Full Model + (1| class $)$ & 0.142 & 0.18 & 0.64 \\
\hline \multirow[t]{2}{*}{ MA16 } & (L.STOR | class $)+$ DIV + PURPOSE + Other Dist & 0.278 & 0.24 & 0.62 \\
\hline & Full Model + (1 | class $)$ & 0.051 & 0.22 & 0.61 \\
\hline \multirow[t]{2}{*}{ MA17 } & Full Model $+(1 \mid$ class $)-$ DIST.MDAM & 0.172 & 0.15 & 0.64 \\
\hline & Full Model + (1| class $)$ & 0.061 & 0.15 & 0.64 \\
\hline \multirow[t]{2}{*}{ MA18 } & Local Dam + Cum Dam + (1| class $)$ & 0.262 & 0.17 & 0.66 \\
\hline & Full Model $+(1 \mid$ class $)$ & 0.050 & 0.18 & 0.66 \\
\hline \multirow[t]{2}{*}{ MA19 } & Full Model $+(1 \mid$ class $)-$ DIST.MDAM & 0.266 & 0.20 & 0.68 \\
\hline & Full Model + (1| class $)$ & 0.095 & 0.20 & 0.68 \\
\hline \multirow[t]{2}{*}{ MA20 } & Local Dam + Cum Dam + (1| class $)$ & 0.511 & 0.19 & 0.72 \\
\hline & Full Model + (1 | class $)$ & 0.032 & 0.19 & 0.72 \\
\hline \multirow{2}{*}{ MA21 } & Local Dam + Cum Dam + (1| class $)$ & 0.233 & 0.14 & 0.68 \\
\hline & Full Model $+(1 \mid$ class $)$ & 0.061 & 0.15 & 0.68 \\
\hline \multirow[t]{2}{*}{ MA22 } & Full Model $+(1 \mid$ class $)-$ DIST.DAM & 0.232 & 0.17 & 0.68 \\
\hline & Full Model $+(1 \mid$ class $)$ & 0.186 & 0.18 & 0.68 \\
\hline \multirow[t]{2}{*}{ MA23 } & Full Model $+(1 \mid$ class $)-$ CANALS & 0.492 & 0.20 & 0.69 \\
\hline & Full Model + (1| class $)$ & 0.260 & 0.20 & 0.69 \\
\hline \multirow[t]{2}{*}{ MA41 } & Local Dam + Other Dist $+(1 \mid$ class $)$ & 0.159 & 0.23 & 0.89 \\
\hline & Full Model + (1| class $)$ & 0.050 & 0.24 & 0.89 \\
\hline \multirow[t]{2}{*}{ ML17 } & (N.STOR | class $)+$ DIV + PURPOSE + Other Dist & 1.000 & 0.26 & 0.67 \\
\hline & Full Model + $(1 \mid$ class $)$ & 0.000 & 0.22 & 0.66 \\
\hline \multirow[t]{2}{*}{ DL1 } & Full Model $+(1 \mid$ class $)-$ DEV & 0.250 & 0.15 & 0.63 \\
\hline & Full Model + (1| class $)$ & 0.089 & 0.15 & 0.63 \\
\hline \multirow[t]{2}{*}{ DL2 } & Full Model $+(1 \mid$ class $)-$ DEV & 0.270 & 0.16 & 0.65 \\
\hline & Full Model + $(1 \mid$ class $)$ & 0.097 & 0.16 & 0.65 \\
\hline \multirow[t]{2}{*}{ DL3 } & Full Model $+(1 \mid$ class $)-$ DEV & 0.278 & 0.18 & 0.66 \\
\hline & Full Model + (1| class $)$ & 0.100 & 0.18 & 0.66 \\
\hline
\end{tabular}




\section{Appendix 1 continued.}

\begin{tabular}{|c|c|c|c|c|}
\hline $\begin{array}{l}\text { Hydrologic } \\
\text { Index }\end{array}$ & Best Model & $\mathrm{AIC}_{\mathrm{c}} \mathrm{Wt}$ & $\mathrm{R}^{2}$ & Class \\
\hline \multirow[t]{2}{*}{ DL4 } & Full Model + (1| class $)-$ DEV & 0.234 & 0.18 & 0.68 \\
\hline & Full Model + $(1 \mid$ class $)$ & 0.084 & 0.18 & 0.68 \\
\hline \multirow[t]{2}{*}{ DL5 } & Full Model $+(1 \mid$ class $)-$ L.STOR & 0.251 & 0.15 & 0.67 \\
\hline & Full Model + (1| class $)$ & 0.117 & 0.16 & 0.69 \\
\hline \multirow[t]{2}{*}{ DL16 } & $($ L.STOR $\mid$ class $)+$ DIV + PURPOSE + Other Dist & 0.899 & 0.20 & 0.73 \\
\hline & Full Model + $(1 \mid$ class $)$ & 0.004 & 0.21 & 0.73 \\
\hline \multirow[t]{2}{*}{ DL18 } & Full Model $+(1 \mid$ class $)-$ N.STOR & 0.204 & 0.10 & 0.72 \\
\hline & Full Model + (1| class $)$ & 0.071 & 0.10 & 0.72 \\
\hline \multirow[t]{2}{*}{ DH1 } & Full Model $+(1 \mid$ class $)-$ PLANT & 0.169 & 0.20 & 0.72 \\
\hline & Full Model + $(1 \mid$ class $)$ & 0.060 & 0.20 & 0.73 \\
\hline \multirow[t]{2}{*}{$\mathrm{DH} 2$} & Full Model + $(1 \mid$ class $)-$ WITHD & 0.154 & 0.15 & 0.69 \\
\hline & Full Model + (1| class $)$ & 0.056 & 0.15 & 0.69 \\
\hline \multirow[t]{2}{*}{ DH3 } & $($ L.STOR $\mid$ class $)+$ DIV + PURPOSE + Other Dist & 0.547 & 0.14 & 0.66 \\
\hline & Full Model + (1|class $)$ & 0.027 & 0.12 & 0.65 \\
\hline \multirow[t]{2}{*}{ DH4 } & Full Model $+(1 \mid$ class $)$ - CANALS & 0.237 & 0.12 & 0.58 \\
\hline & Full Model + $(1 \mid$ class $)$ & 0.090 & 0.12 & 0.58 \\
\hline \multirow[t]{2}{*}{ DH5 } & Full Model + (1 | class $)$ - DIST.DAM & 0.266 & 0.13 & 0.56 \\
\hline & Full Model + (1 | class $)$ & 0.110 & 0.13 & 0.56 \\
\hline \multirow[t]{2}{*}{ DH15 } & (N.STOR | class $)+$ DIV + PURPOSE + Other Dist & 0.999 & 0.15 & 0.70 \\
\hline & Full Model + (1 | class $)$ & 0.000 & 0.13 & 0.70 \\
\hline \multirow[t]{2}{*}{ TA2 } & (L.STOR | class $)+$ DIV + PURPOSE + Other Dist & 1.000 & 0.18 & 0.62 \\
\hline & Full Model + $(1 \mid$ class $)$ & 0.000 & 0.15 & 0.61 \\
\hline \multirow[t]{2}{*}{ FL1 } & Full Model + $(1 \mid$ class $)-$ PLANT & 0.209 & 0.23 & 0.67 \\
\hline & Full Model $+(1 \mid$ class $)$ & 0.080 & 0.23 & 0.67 \\
\hline \multirow[t]{2}{*}{ FH1 } & Full Model + (1| class $)$ - DIST.DAM & 0.187 & 0.14 & 0.73 \\
\hline & Full Model + (1 | class $)$ & 0.066 & 0.14 & 0.73 \\
\hline \multirow[t]{2}{*}{ FH6 } & Full Model $+(1 \mid$ class $)$ - DIST.MDAM & 0.137 & 0.11 & 0.83 \\
\hline & Full Model + (1| class $)$ & 0.050 & 0.11 & 0.83 \\
\hline \multirow[t]{2}{*}{ RA1 } & Full Model + $(1 \mid$ class $)$ - DIST.DAM & 0.162 & 0.18 & 0.73 \\
\hline & Full Model + (1 | class $)$ & 0.061 & 0.18 & 0.73 \\
\hline \multirow[t]{2}{*}{ RA3 } & Full Model $+(1 \mid$ class $)-$ IRRIG & 0.220 & 0.20 & 0.66 \\
\hline & Full Model + $(1 \mid$ class $)$ & 0.083 & 0.20 & 0.66 \\
\hline \multirow[t]{2}{*}{ RA8 } & Full Model + $(1 \mid$ class $)-$ PLANT & 0.268 & 0.31 & 0.68 \\
\hline & Full Model + $(1 \mid$ class $)$ & 0.106 & 0.31 & 0.69 \\
\hline \multirow[t]{2}{*}{$\mathrm{D}$} & Full Model $+(1 \mid$ class $)-$ D.DENS & 0.193 & 0.19 & NA \\
\hline & Full Model + $(1 \mid$ class $)$ & 0.070 & 0.19 & NA \\
\hline
\end{tabular}




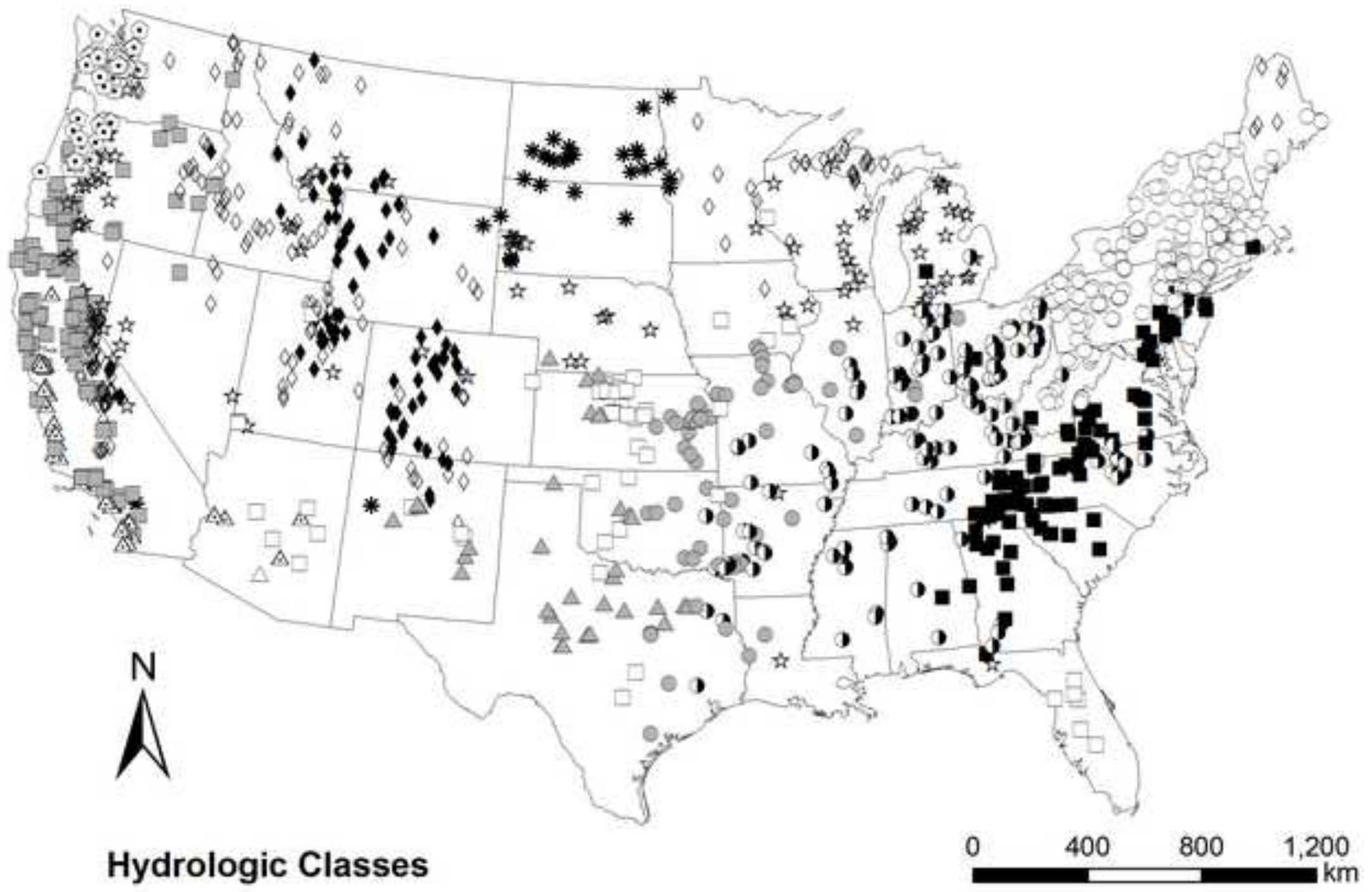

[- Late Timing Runoff

t2 Super-Stable Groundwater

- Unpredictable Intermittent

$\Delta \quad$ Harsh Intermittent

- Perennial Runoff 1

- Stable High Baseflow

$\Delta$ Intermittent Flashy 2

- Snowmelt 1

C. Perennial Runoff 2

A Intermittent Flashy SW

D Western Coastal Runoff

Snowmelt 2

- Stable High Runoff 

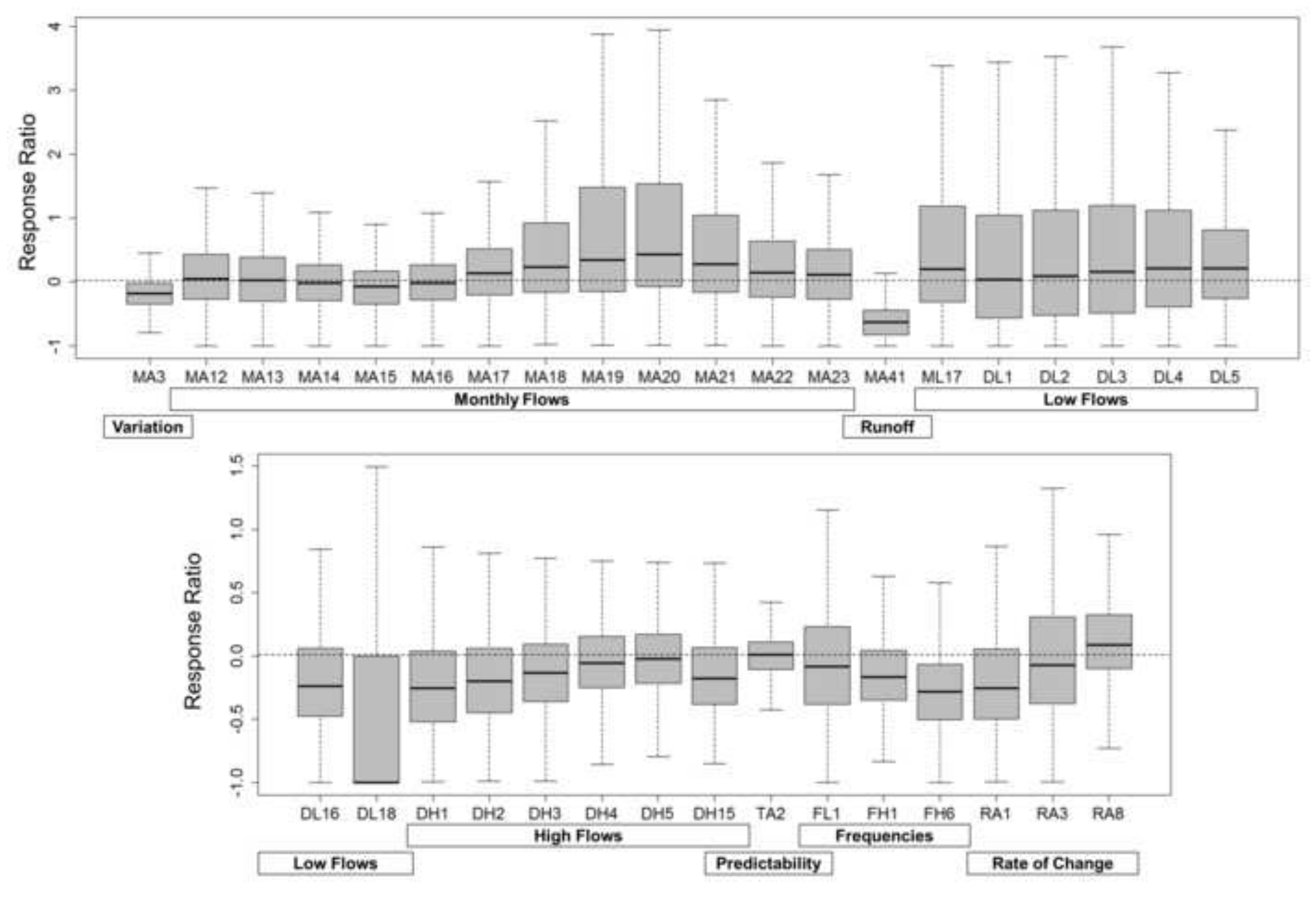

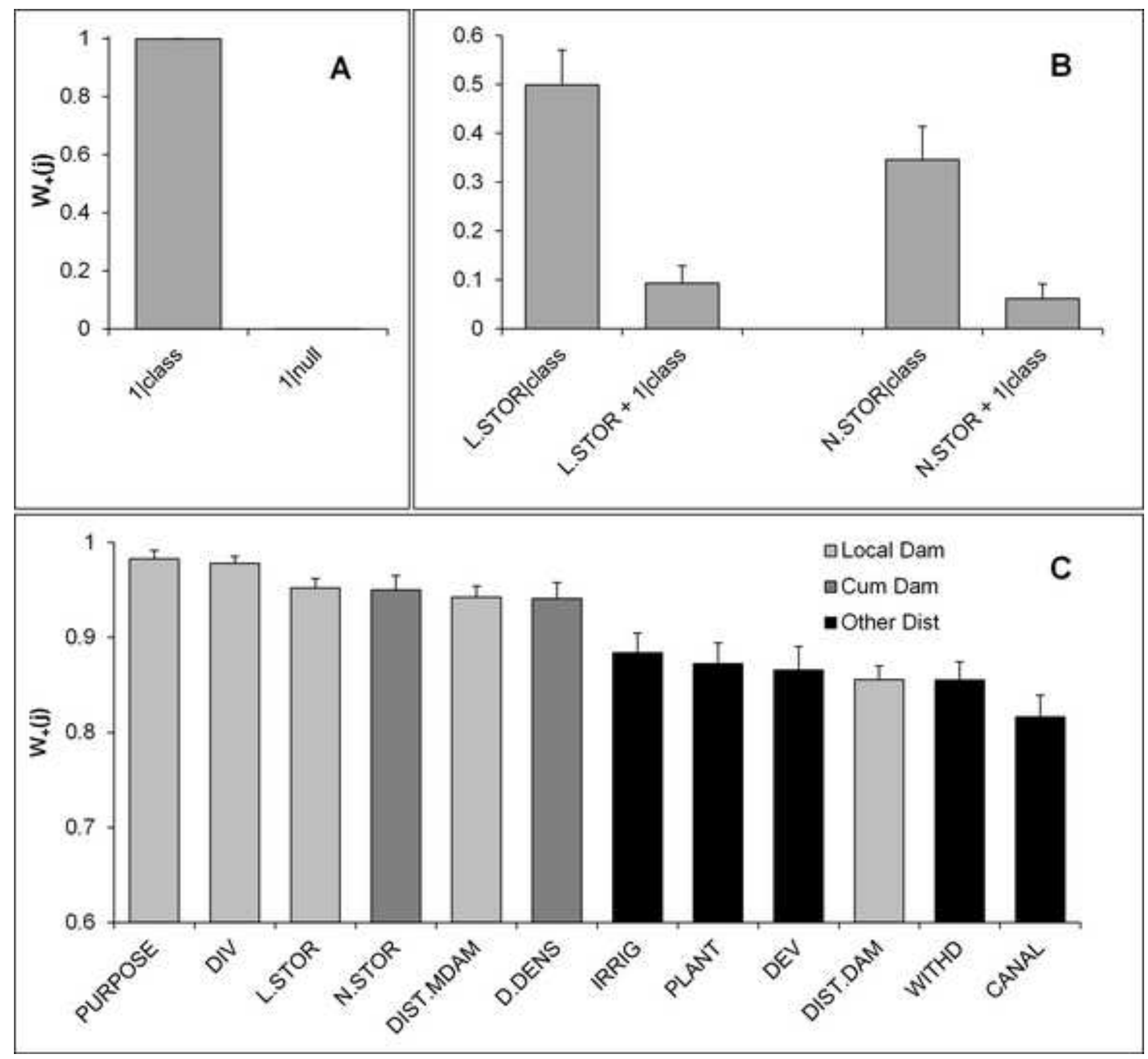


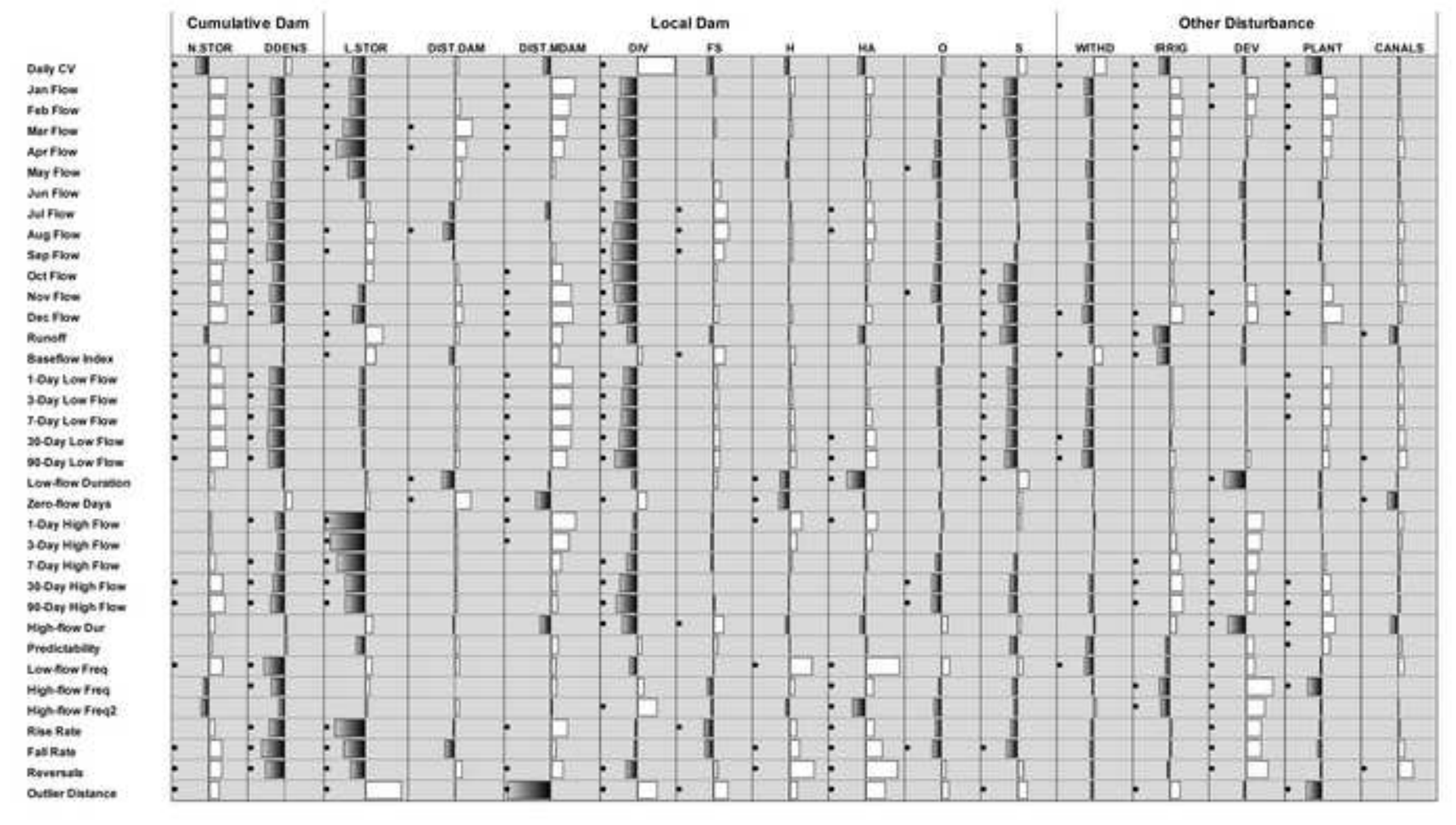

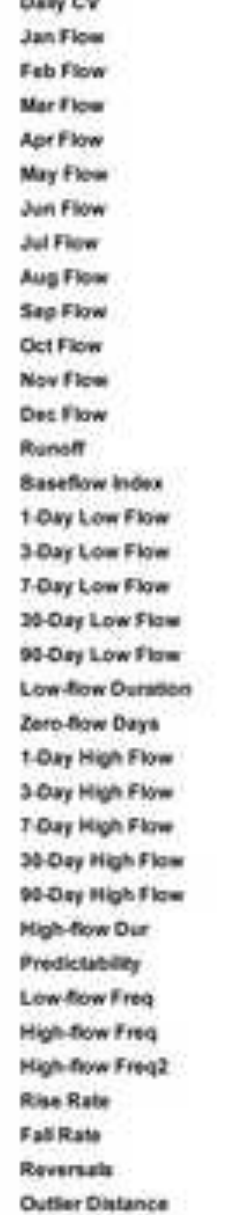

Outler Dintan
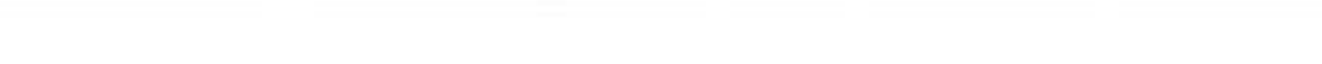

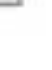



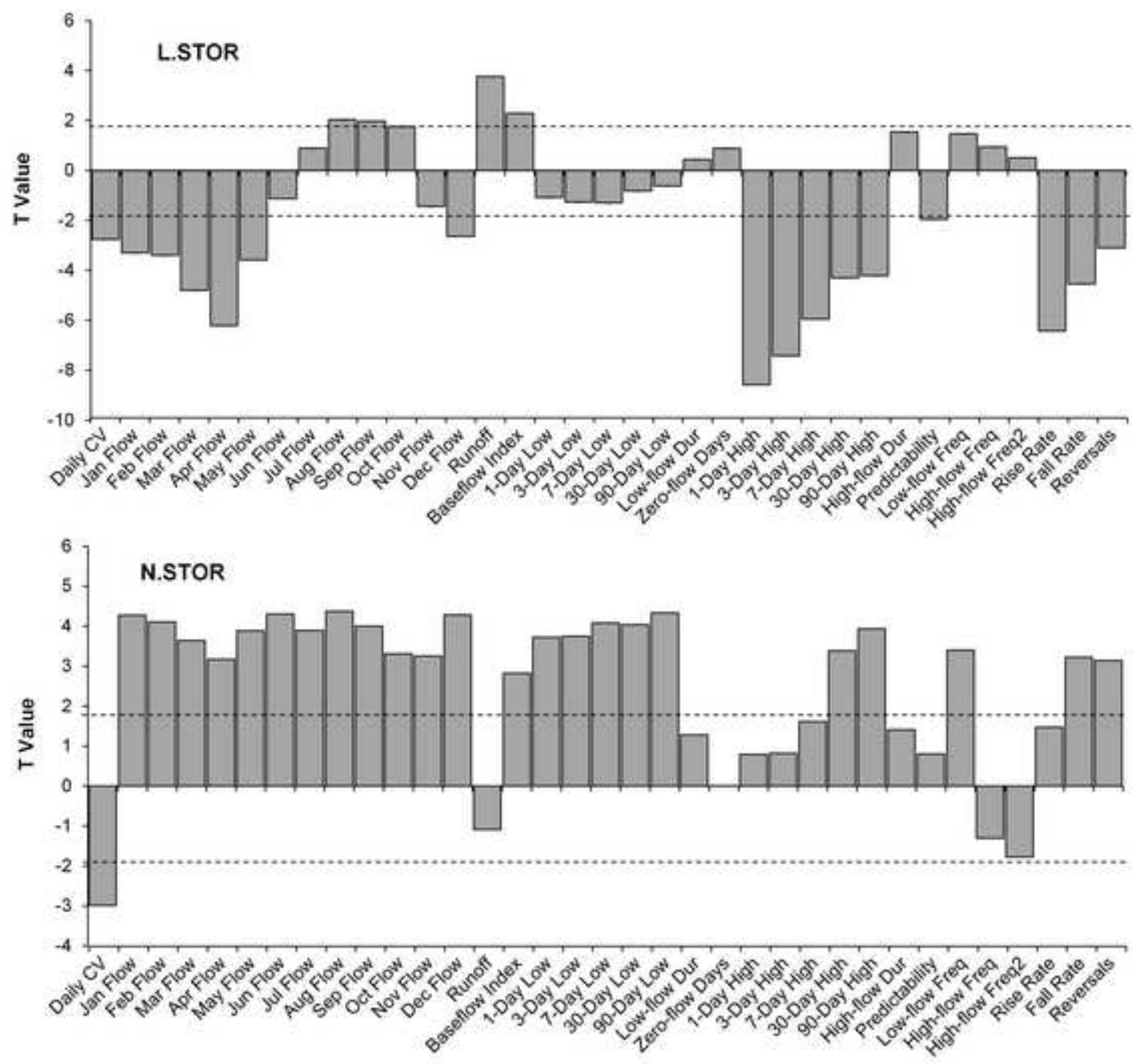

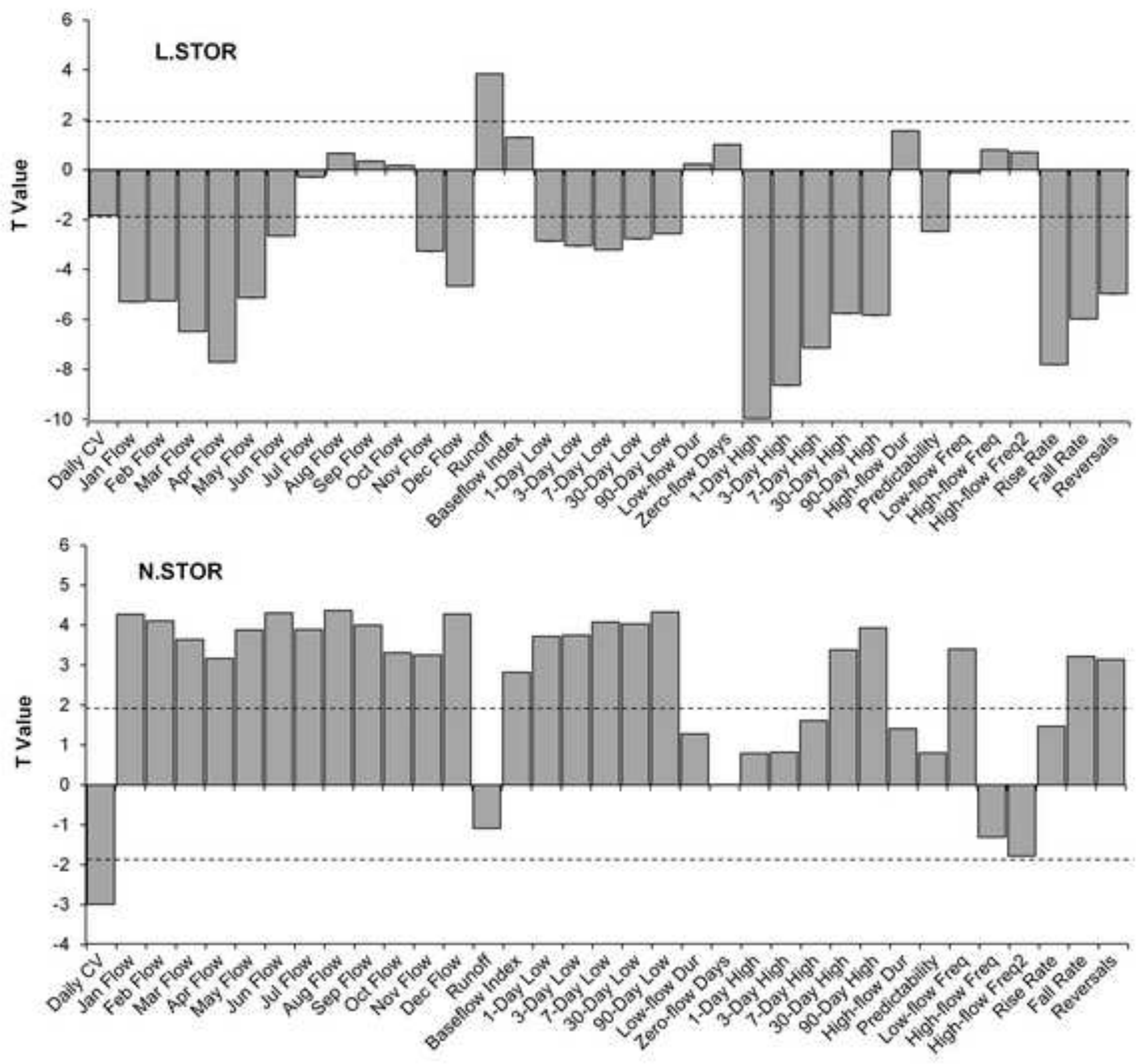
Hydrologic Classes

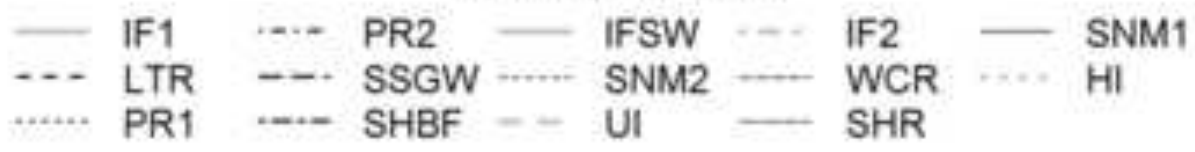
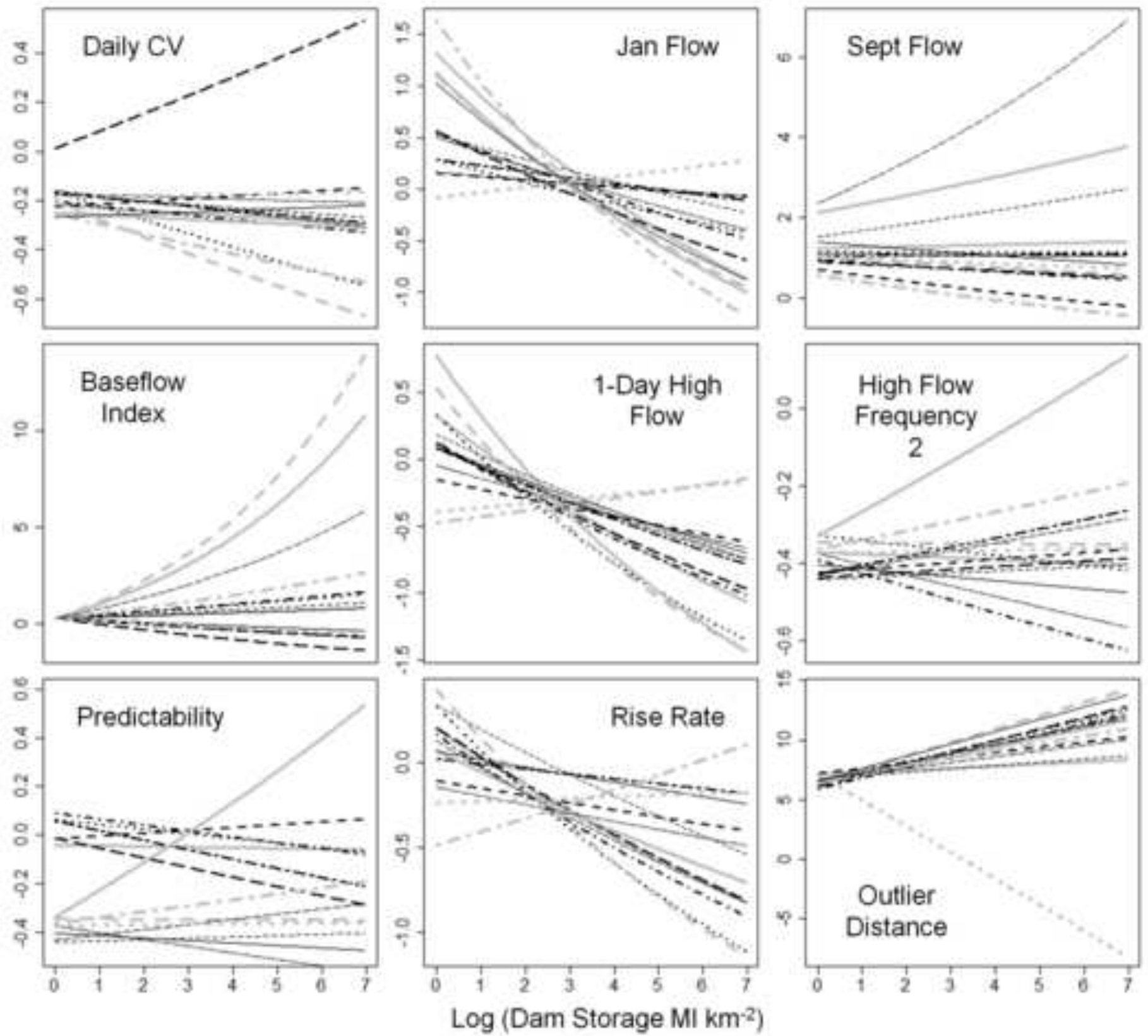

Log (Dam Storage Ml km-2) 

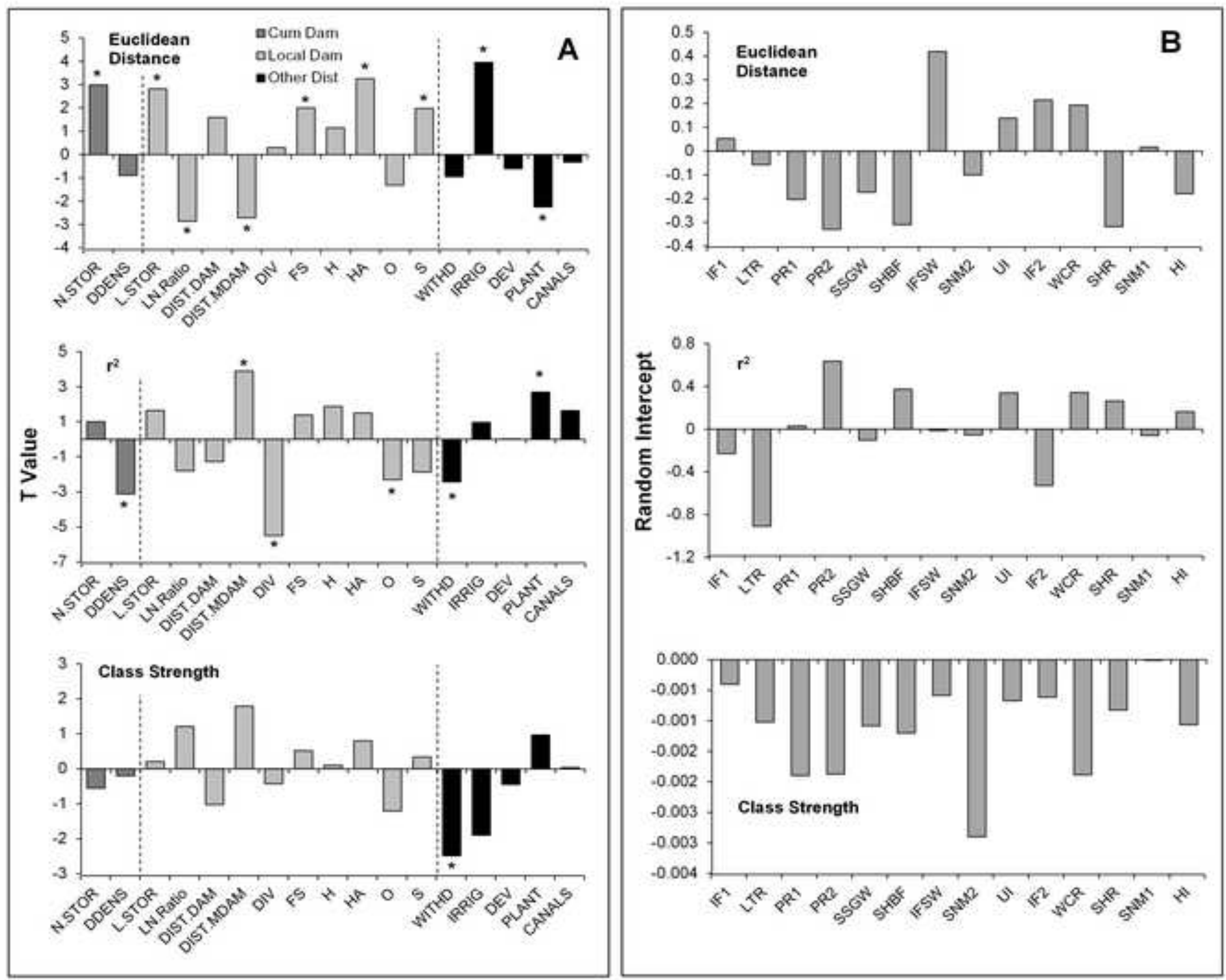

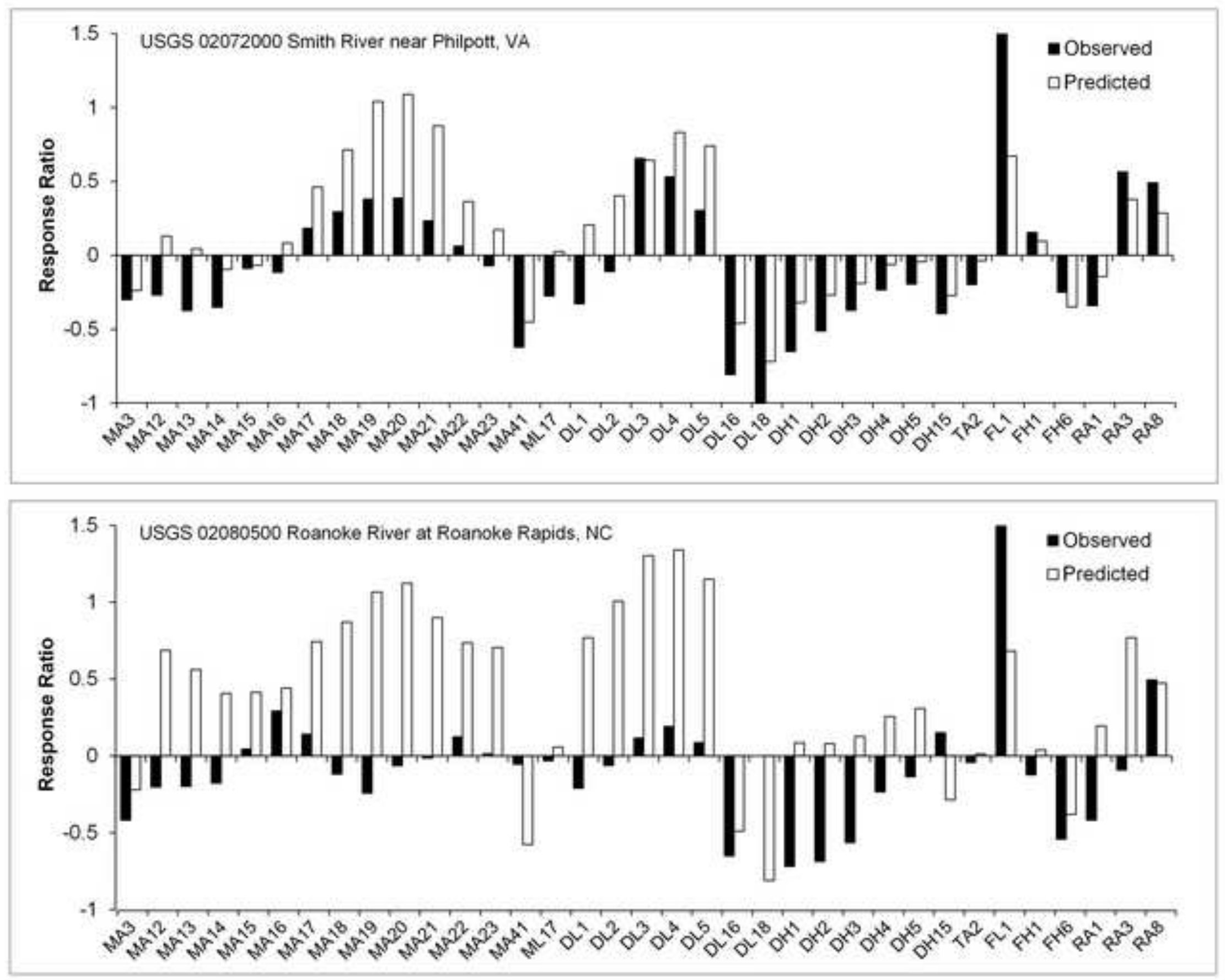

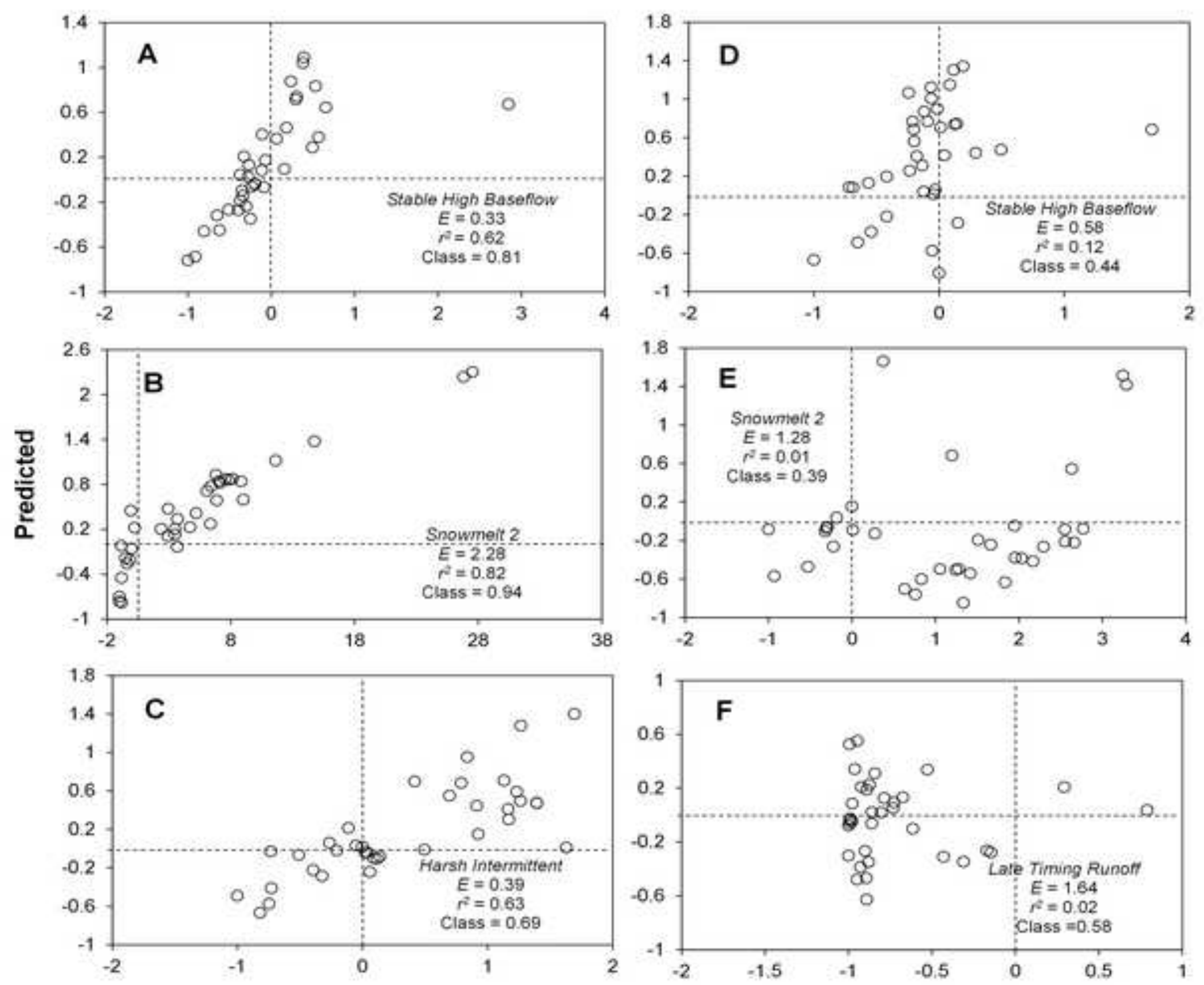

Observed 